\title{
Resurrection of human endogenous retroviruses during aging reinforces senescence
}

\author{
Xiaoqian Liu ${ }^{1,7, \#}$, Zunpeng Liu ${ }^{1,7, \#, ~ L i a n g ~}$ Sun $^{9}$, Jie Ren ${ }^{4,5,6,7}$, Zeming $\mathrm{Wu}^{1,7}$, Xiaoyu Jiang ${ }^{2,7}$, \\ Qianzhao Ji ${ }^{2,7}$, Qianran Wang ${ }^{3,4,7}$, Yanling Fan ${ }^{3,4,7}$, Yusheng Cai ${ }^{2,7}, \mathrm{Si}^{2} \mathrm{Wang}^{2,6,7}$, Wei $\mathrm{Li}^{3}$, Gang Cao ${ }^{8}$, \\ Moshi Song ${ }^{2,6,7}$, Falong $\mathrm{Lu}^{7,10}$, Weiqi Zhang ${ }^{4,5,6,7, *}$, Jing $\mathrm{Qu}^{1,6,7, *}$, Guang-Hui Liu ${ }^{2,3,6,7, *}$
}

${ }^{1}$ State Key Laboratory of Stem Cell and Reproductive Biology, Institute of Zoology, Chinese Academy of Sciences, Beijing 100101, China

${ }^{2}$ State Key Laboratory of Membrane Biology, Institute of Zoology, Chinese Academy of Sciences, Beijing 100101, China

${ }^{3}$ Advanced Innovation Center for Human Brain Protection, National Clinical Research Center for Geriatric Disorders, Xuanwu Hospital Capital Medical University, Beijing 100053, China

${ }^{4}$ CAS Key Laboratory of Genomic and Precision Medicine, Beijing Institute of Genomics, Chinese Academy of Sciences, Beijing 100101, China

${ }^{5}$ China National Center for Bioinformation, Beijing 100101, China

${ }^{6}$ Institute for Stem cell and Regeneration, CAS, Beijing 100101, China

${ }^{7}$ University of Chinese Academy of Sciences, Beijing 100049, China

${ }^{8}$ State Key Laboratory of Agricultural Microbiology, Huazhong Agricultural University, Wuhan 430070

${ }^{9}$ The MOH Key Laboratory of Geriatrics, Beijing Hospital, National Center of Gerontology, Beijing 100730, China

${ }^{10}$ State Key Laboratory of Molecular Developmental Biology, Institute of Genetics and Developmental Biology, The Innovative Academy of Seed Design, Chinese Academy of Sciences, Beijing 100101, China

\# Contributed equally

*Correspondence: ghliu@ioz.ac.cn (GHL), qujing@ioz.ac.cn (JQ), zhangwq@big.ac.cn (WZ) 


\begin{abstract}
Human endogenous retroviruses (HERVs) are under strict control by the host surveillance system but can become awakened under pathological conditions. Among them, the HERVK family, comprised of the evolutionarily youngest HERVs, is able to transcribe viral genes and producing retrovirus-like particles (RVLPs). However, whether HERVK is mobilized in the aging process and contributes to aging-related pathologies is largely unknown. Using diverse senescence models, we show that epigenetic alterations unlock HERVK expression, which leads to the formation of RVLPs. Derepression of HERVK promotes cellular senescence, while inhibiting HERVK prevents cellular senescence. HERVK RVLPs released from senescent cells or aged individuals are capable of conferring a senescence phenotype to young cells. Conversely, using antibodies to block the HERVK RVLPs abrogates their transmissible pro-senescence effect. Moreover, endogenous retrovirus expression is increased in aged human tissues and serum from the elderly. These findings indicate that the activation of endogenous viruses is part of the driving force of aging.
\end{abstract}

\title{
Main Text
}

Aging progressively leads to physiological decline and manifestations of chronic diseases, yet many of the underlying molecular changes and mechanisms remain poorly understood. Elucidating the basic mechanisms is fundamental for the development of therapeutic interventions to delay aging. With great efforts of last decades, scientists have identified several causal determinants of aging-related molecular changes, such as epigenetic alterations and stimulation of senescence-associated secretory phenotype (SASP) factors (1-7). However, the majority of these studies originated extensively from the protein-coding part of the genome, and much less have been revealed in the non-protein-coding part of the genome. Therefore we turned our attention to retroelements, the "dark matter" of the genome (8), and its uncharted role in aging.

Retroelements, such as long terminal repeat (LTR) and non-LTR retrotransposons, constitute approximately $42 \%$ of the human genome (9). Among them, human endogenous retroviruses (HERVs), which belong to LTR retrotransposons, are a relic of ancient retroviral infection, fixed in the genome during evolution, comprising about $8 \%$ of the human genome $(10,11)$. Due to the evolutionary pressure, most HERVs became defective as they accumulated inactivating mutations and deletions that prevent their mobilization $(10,12)$. However, HERVK, the evolutionarily youngest group of HERVs, maintains full-length open reading frames encoding proteins required for viral particle formation, including Gag, Pol, Env, and Pro (11). In most cases, HERVs are transcriptionally silenced by host mechanisms such as epigenetic regulation, including DNA methylation and histone modifications (13, 14). However, if it is able to bypass host surveillance, HERVK retroviral elements start to transcribe, 
retrotranspose, and even produce and release retrovirus-like particles (RVLPs) capable of infecting human cells $(15,16)$. As aging is associated with changes in the epigenome $(3,17)$, in this study, we asked whether dormant HERVK might become activated during human aging, whether the mobilization of HERVK is a driving force of aging, and whether it can be a potential therapeutic target to alleviate aging.

\section{Precocious HERVK expression and RVLPs packaging in senescent human cells}

Cellular senescence is considered as a major contributing factor to aging $(2,18)$ and is a hallmark of human progeroid diseases, i.e., Hutchinson-Gilford progeria syndrome (HGPS) and Werner syndrome (WS) (19-24). We previously demonstrated that HGPS human mesenchymal progenitor cells (hMPCs) $\left(L M N A^{\mathrm{G} 608 \mathrm{G} /+} \mathrm{hMPCs}\right)$ or WS hMPCs (WRN $\left.{ }^{/-} \mathrm{hMPCs}\right)$ recapitulated premature aging phenotypes (2025) (Fig.1A). Here, we leverage these premature aging models as well as wild type (WT) replicative senescent (RS) hMPCs (Fig. 1A) to test whether HERVK activation is associated with human cellular senescence.

To investigate whether retroelements (REs) are actively transcribed during cellular senescence, we performed RNA-seq analysis in WT RS hMPCs and prematurely aged models including HGPS and WS hMPCs (Fig. 1A-B). We found increased expression of several transposable elements in senescent hMPCs, such as LTR, DNA transposons and LINE (Long interspersed nuclear elements, a class of non-LTR) (Fig. 1B). Of these elements, retroelement HERVK-int in ERVK family, was upregulated in both replicative and prematurely aged hMPCs (Fig. 1B). We were particularly interested in HERVK, as it is the only HERV retroelement family still active in human $(15,16)$. We also discovered that the most recently integrated provirus subfamily of HERVK, HML2 (human mouse mammary tumour virus like-2) (11), was highly activated in senescent hMPCs (Fig. 1C). Using primers targeting different regions of HERVK transcripts, including Env, Pol, and Gag (26) (Fig. 1A), we confirmed that HERVK retroelements were highly expressed during cellular senescence by RT-qPCR, showing a similar pattern of increase with the senescence marker $p 21^{\text {Cipl }}$, while Lamin-associated protein LAP2 (TMPO) decreased during senescence as reported previously (27) (Fig. 1D). Likewise, RNA fluorescence in situ hybridization (RNA-FISH) analysis also showed increased cytoplasmic HERVK RNA signals in HGPS and WS hMPCs compared to WT hMPCs (Fig. 1E).

Consistent with activated HERVK transcription in aged hMPCs, we observed a reduced level of global DNA methylation in the entire HERVK family in both prematurely aged hMPCs (Fig. 1F). Chromatin immunoprecipitation (ChIP)-qPCR further showed that HERVK activation was correlated with a decrease of the repressive histone mark (H3K9me3) at the HERVK-LTR5HS in aged hMPCs (Fig. $1 \mathrm{G})$. These data indicate that the epigenetic derepression of HERVK loci, likely contributing to HERVK transcription, is associated with cellular aging. 
Next, we asked whether unconstrained endogenous retrovirus expression elicits the production of HERVK protein components, the retrotransposition, and even the formation of RVLPs. Western blotting and immunofluorescence analyses showed increased HERVK-Env protein levels in prematurely aged hMPCs (Fig. 1H-I). In line with increased levels of HERVK retroelement RNA and protein, immuno-TEM analysis with an anti-HERVK-Env antibody (28) showed that HERVK formed RVLPs in senescent cells with a diameter ranging from 80 to $120 \mathrm{~nm}$ (Fig. 1J). Cumulatively, these data present evidences of HERVK activation, mobilization and packaging in senescent cells.

\section{HERVK expression triggers innate immune response and cellular senescence}

To determine whether the cellular consequences caused by activation of endogenous HERVK, we used a CRISPR-dCas9 transcriptional activation system containing activation protein complexes (synergistic activation mediators, SAM) with sgRNA targeting to HERVK-LTR5HS promoter region (29) (Fig. 2A) and confirmed activation of the HERVK endogenous retrotransposon elements by western blotting (Fig. 2B). We found that HERVK activation caused hMPC senescence, as evidenced by an increased relative percentage of senescence-associated $\beta$-galactosidase (SA- $\beta$-gal)-positive cells (Fig. 2C). To further assess whether endogenous HERVK activation is a driving force of cellular senescence, we used HERVK-specific shRNA (Fig. 2A, D) $(26,30)$ to knock down HERVK in prematurely aged hMPCs and found that repression of HERVK alleviated hMPC senescence (Fig. 2E).

HERVK-encoded Pol protein possesses reverse transcription activity that can reverse-transcribe HERVK RNA into DNA $(10,11)$, thereby generating additional HERVK DNA outside of the genome. Consistent with increased HERVK RNA (Fig. 1E), we also observed a concomitantly increased HERVK DNA in the cytoplasm of aged hMPCs by single molecule DNA-FISH (Fig. 2F). These excessive cytoplasmic DNA may be recognized by the key DNA sensor cGMP-AMP synthase (cGAS) and trigger innate immune response (Fig. 2G) (33, 34). Immunoprecipitation analysis verified increased cGAS enrichment on the cytoplasmic HERVK DNA in senescent hMPCs, whereas it was hardly enriched in early-passage younng hMPCs, indicating that the presence of cytosolic HERVK DNA triggers activation of cGAS-STING pathway (Fig. 2H). To further investigate the activation state of the cGAS-STING DNA-sensing pathway, we examined key features including the second messenger 2'3'-cGAMP, phosphorylation of RelA/NF- $\kappa B$, TANK-binding kinase 1 (TBK1), and IFN regulatory factor 3 (IRF3), as well as proinflammatory cytokine expression in aged hMPCs (Fig. 2G) (33). As expected, we observed an increase in 2'3'-cGAMP content, phosphorylation of TBK1, RelA and IRF3, and the upregulation of inflammatory cytokines including $I L 6$, classified as SASP factors $(35,36)$ in senescent hMPCs (Fig. 2J-K). Knockdown of HERVK alleviated cellular senescence and SASP (Fig. 2L). In contrast, activation of endogenous HERVK via the CRISPR-dCas9 system led to an increase in the levels of phosphorylated TBK1, RelA, and IRF3, and upregulated expression of 
SASP cytokines in hMPCs (Fig. 2M-N). All these data place induced HERVK expression as a contributing factor for cellular senescence, at least in part by activating the innate immunity pathway.

\section{Extracellular HERVK induces cellular senescence}

Given the presence of HERVK RVLPs in aged cells and previous studies showing that HERVK RVLPs produced by tumor cells are released into the medium and taken up by human cells (37), we asked whether HERVK RVLPs produced by senescent cells could be released extracellularly and convey senescence signals to non-senescent cells (Fig. 3A). To answer this question, we employed a sensitive droplet digital PCR (ddPCR) technology to detect the level of HERVK RNA, which is the genetic material packaged in RVLPs $(10,11,38)$, in the conditioned medium (CM) harvested from WT and prematurely senescent hMPCs. We found that HERVK RNA level was 5 12 times higher in CM from prematurely senescent hMPCs compared with that from WT hMPCs (Fig. 3B). In addition, ELISA assay demonstrated increased HERVK-Env protein levels in the medium of senescent hMPCs (Fig. 3C). Based on Immuno-TEM images, we detected RVLPs outside the cells with diameters spanning from 80 to $120 \mathrm{~nm}$, that were mainly present in aged hMPCs (Fig. 3D).

We next treated young hMPCs (WT) with CM collected from HGPS, WS, or RS hMPCs (collectively called "old" CM), using CM collected from young WT hMPCs as control (Fig. 3E). With TEM analysis, we found that extracellular RVLPs derived from old CM adhered to the cell surface of young hMPCs (Fig. 3F). After the old CM treatment, we observed an increase in HERVK RNA in young hMPCs (Fig. 3G), implying that HERVK in the old CM may be transmitted into targeted cells. Moreover, we found that the invaded HERVK elements was associated with an "aging-promoting" effect, that is, to induce accelerated cellular senescence in young hMPCs which were incubated with old CM (Fig. 3H).

To further investigate whether HERVK from the old CM is one of the major factors that cause senescence in young hMPCs, we then immuno-depleted HERVK in old CM using an anti-HERVKEnv antibody (39) (Fig. 3I). Immuno-depletion of HERVK from the old CM resulted in HERVK RNA reduction and alleviation of senescence phenotypes in young WT hMPCs as compared to those treated with old CM without immune-depletion (Fig. 3J-K). Collectively, the data above suggest that retroviral HERVK elements generated in aged cells can be released in a paracrine manner and trigger cellular senescence in recipient young cells.

\section{Human endogenous retrovirus can be used as a biomarker of aging}

Next, we sought to investigate whether elevated activation of human endogenous retrovirus HERVK is observed in human cells and organs during physiological aging. Indeed, we found that HERVK activation was pronounced in primary hMPCs derived from old individuals relative to their younger counterparts (Fig. 4A-B) (21, 43-46). Likewise, in skin tissues obtained from young and old donors, 
HERVK-Env expression was markedly increased with age (Fig. 4A, C). More importantly, ELISA analysis of human serum revealed increased HERVK-Env level in the serum from old individuals relative to that from young individuals (Fig. 4A, D). Taken together, these results indicate that human endogenous retrovirus HERVK may be used as a potential biomarker to assess human aging, and a potential therapeutic target to alleviate senescence.

\section{Discussion}

In this study, we discovered a positive feedback loop between human endogenous retrovirus HERVK activation and aging, represented as human endogenous retrovirus HERVK robustly activated across several aging models, which conversely enhances senescence. Our comprehensive analysis revealed several causal relationships: 1) Epigenetic derepression of HERVK leads to the accumulation of HERVK RNA, protein, and RVLPs in aged human cells; 2) Activation of endogenous HERVK is sufficient to promote cellular senescence partially through the activation of innate immunity pathway, while inactivation of HERVK alleviates senescence in various human aging models; 3) HERVK RVLPs can be secreted from aged cells in a paracrine manner and induce senescence in young cells; 4) Using antibodies to block the HERVK particles released from senescent cells abrogates their transmissible pro-senescence effect; 5) HERV activation is a characteristic of old human tissues, and the accumulation of circulating HERVK can be used as a potential serum biomarker for clinical aging assessment, and a potential therapeutic target for aging intervention (Fig. 5).

Based on these data, we hypothesize that HERVK functions as both a consequence and cause of aging. Although HERVK has not directly been implicated in the regulation of human aging, several studies have established a correlation between awakened HERVK retrovirus and aging-related disorders, such as rheumatoid arthritis (47-49) and neurodegenerative diseases (29, 39, 50-54). Notably, RVLPs produced by HERVK are known as a cancer indicator $(28,55)$, which may be due to (epi)genetic instabilities accumulated in cancer cells. We have demonstrated that aging-related HERVK activation is tuned by the cellular epigenetic clock, including DNA methylation and histone modifications (13, 53, 56). Thus, the presence of HERVK RVLPs both in the cytoplasm and the extracellular spaces is thereby likely indicative of accumulated (epi)genetic aberrations in aged cells. However, at tissue levels, whether HERVK is activated in specific organs/tissues and transmissible as a pro-senescence factor acros sorgans/tissues, and whether resurrection of endogenous retrovirus is conserved among other non-human species need to be further investigated. Therefore, future studies are in demand, such as to characterize endogenous retrovirus expression profiles across ages and species in large populations and examine the results with other aging clocks, e.g., DNA methylation and telomere length, et al. 
bioRxiv preprint doi: https://doi.org/10.1101/2021.02.22.432260; this version posted February 22, 2021. The copyright holder for this preprint (which was not certified by peer review) is the author/funder, who has granted bioRxiv a license to display the preprint in perpetuity. It is made available under aCC-BY-NC-ND 4.0 International license.

We demonstrated that HERVK viral components could activate cellular innate immune sensors, including the cGAS-STING pathway, to initiate inflammatory responses and to trigger cellular senescence $(33,57-60)$. It should be mentioned that mobilization of HERV repetitive sequences may cause genomic mutagenesis and abnormal chromosomal rearrangements $(61,62)$, which may also underlie HERVK-mediated pro-senescence events. Lastly, given that several antiretroviral drugs that can inhibit HERVK activity in the cells have been approved by Food and Drug Administration (FDA) (63), that HERVK-targeted cancer immunotherapies have also been reported $(64,65)$, and that antibodies of HERVK can block the pro-senescence effect of HERVK in our study, HERVK represents a druggable target for alleviating aspects of aging and improving overall human health.

\section{References and Notes}

1. T. Tchkonia, A. K. Palmer, J. L. Kirkland, New Horizons: Novel Approaches to Enhance Healthspan Through Targeting Cellular Senescence and Related Aging Mechanisms. The Journal of clinical endocrinology and metabolism, (2020); published online EpubNov 6 (10.1210/clinem/dgaa728).

2. J. Campisi, P. Kapahi, G. J. Lithgow, S. Melov, J. C. Newman, E. Verdin, From discoveries in ageing research to therapeutics for healthy ageing. Nature 571, 183-192 (2019); published online EpubJul (10.1038/s41586-019-1365-2).

3. W. Zhang, J. Qu, G. H. Liu, J. C. I. Belmonte, The ageing epigenome and its rejuvenation. Nature reviews. Molecular cell biology 21, 137-150 (2020); published online EpubMar (10.1038/s41580-019-0204-5).

4. C. Lopez-Otin, G. Kroemer, Hallmarks of Health. Cell, (2020); published online EpubDec 15 (10.1016/j.cell.2020.11.034).

5. S. Horvath, K. Raj, DNA methylation-based biomarkers and the epigenetic clock theory of ageing. Nature reviews. Genetics 19, 371-384 (2018); published online EpubJun (10.1038/s41576-018-0004-3).

6. R. Ren, A. Ocampo, G. H. Liu, J. C. Izpisua Belmonte, Regulation of Stem Cell Aging by Metabolism and Epigenetics. Cell Metab 26, 460-474 (2017); published online EpubSep 5 (10.1016/j.cmet.2017.07.019).

7. S. Ahadi, W. Zhou, S. M. Schussler-Fiorenza Rose, M. R. Sailani, K. Contrepois, M. Avina, M. Ashland, A. Brunet, M. Snyder, Personal aging markers and ageotypes revealed by deep longitudinal profiling. Nat Med 26, 83-90 (2020); published online EpubJan (10.1038/s41591019-0719-5).

8. P. Kapranov, G. St Laurent, Genomic "dark matter": implications for understanding human disease mechanisms, diagnostics, and cures. Frontiers in genetics 3, 95 (2012)10.3389/fgene.2012.00095).

9. J. Jurka, V. V. Kapitonov, O. Kohany, M. V. Jurka, Repetitive Sequences in Complex Genomes: Structure and Evolution. Annual Review of Genomics and Human Genetics 8, 241259 (2007)10.1146/annurev.genom.8.080706.092416).

10. W. E. Johnson, Origins and evolutionary consequences of ancient endogenous retroviruses. Nature reviews. Microbiology 17, 355-370 (2019); published online EpubJun (10.1038/s41579-019-0189-2).

11. V. Blikstad, F. Benachenhou, G. O. Sperber, J. Blomberg, Evolution of human endogenous retroviral sequences: a conceptual account. Cellular and molecular life sciences : CMLS 65, 3348-3365 (2008); published online EpubNov (10.1007/s00018-008-8495-2). 
bioRxiv preprint doi: https://doi.org/10.1101/2021.02.22.432260; this version posted February 22, 2021. The copyright holder for this preprint (which was not certified by peer review) is the author/funder, who has granted bioRxiv a license to display the preprint in perpetuity. It is made available under aCC-BY-NC-ND 4.0 International license.

12. J. P. Stoye, Studies of endogenous retroviruses reveal a continuing evolutionary saga. Nature reviews. Microbiology 10, 395-406 (2012); published online EpubMay 8 (10.1038/nrmicro2783).

13. T. P. Hurst, G. Magiorkinis, Epigenetic Control of Human Endogenous Retrovirus Expression: Focus on Regulation of Long-Terminal Repeats (LTRs). Viruses 9, (2017); published online EpubMay 31 (10.3390/v9060130).

14. C. H. Tie, H. M. Rowe, Epigenetic control of retrotransposons in adult tissues: implications for immune regulation. Current opinion in virology 25, 28-33 (2017); published online EpubAug (10.1016/j.coviro.2017.06.007).

15. P. Villesen, L. Aagaard, C. Wiuf, F. S. Pedersen, Identification of endogenous retroviral reading frames in the human genome. Retrovirology 1, 32 (2004); published online EpubOct $11(10.1186 / 1742-4690-1-32)$.

16. M. Garcia-Montojo, T. Doucet-O'Hare, L. Henderson, A. Nath, Human endogenous retrovirus-K (HML-2): a comprehensive review. Critical reviews in microbiology 44, 715-738 (2018); published online EpubNov (10.1080/1040841X.2018.1501345).

17. W. Zhang, M. Song, J. Qu, G. H. Liu, Epigenetic Modifications in Cardiovascular Aging and Diseases. Circulation research 123, 773-786 (2018); published online EpubSep 14 (10.1161/CIRCRESAHA.118.312497).

18. C. Lopez-Otin, M. A. Blasco, L. Partridge, M. Serrano, G. Kroemer, The hallmarks of aging. Cell 153, 1194-1217 (2013); published online EpubJun 6 (10.1016/j.cell.2013.05.039).

19. B. A. Kudlow, B. K. Kennedy, R. J. Monnat, Jr., Werner and Hutchinson-Gilford progeria syndromes: mechanistic basis of human progeroid diseases. Nature reviews. Molecular cell biology 8, 394-404 (2007); published online EpubMay (10.1038/nrm2161).

20. G. H. Liu, B. Z. Barkho, S. Ruiz, D. Diep, J. Qu, S. L. Yang, A. D. Panopoulos, K. Suzuki, L. Kurian, C. Walsh, J. Thompson, S. Boue, H. L. Fung, I. Sancho-Martinez, K. Zhang, J. Yates, 3rd, J. C. Izpisua Belmonte, Recapitulation of premature ageing with iPSCs from HutchinsonGilford progeria syndrome. Nature 472, 221-225 (2011); published online EpubApr 14 (10.1038/nature09879).

21. W. Zhang, J. Li, K. Suzuki, J. Qu, P. Wang, J. Zhou, X. Liu, R. Ren, X. Xu, A. Ocampo, T. Yuan, J. Yang, Y. Li, L. Shi, D. Guan, H. Pan, S. Duan, Z. Ding, M. Li, F. Yi, R. Bai, Y. Wang, C. Chen, F. Yang, X. Li, Z. Wang, E. Aizawa, A. Goebl, R. D. Soligalla, P. Reddy, C. R. Esteban, F. Tang, G. H. Liu, J. C. Belmonte, Aging stem cells. A Werner syndrome stem cell model unveils heterochromatin alterations as a driver of human aging. Science (New York, N.Y.) 348, 1160-1163 (2015); published online EpubJun 5 (10.1126/science.aaa1356).

22. Z. Wu, W. Zhang, M. Song, W. Wang, G. Wei, W. Li, J. Lei, Y. Huang, Y. Sang, P. Chan, C. Chen, J. Qu, K. Suzuki, J. C. I. Belmonte, G. H. Liu, Differential stem cell aging kinetics in Hutchinson-Gilford progeria syndrome and Werner syndrome. Protein \& cell 9, 333-350 (2018); published online EpubApr (10.1007/s13238-018-0517-8).

23. L. Geng, Z. Liu, W. Zhang, W. Li, Z. Wu, W. Wang, R. Ren, Y. Su, P. Wang, L. Sun, Z. Ju, P. Chan, M. Song, J. Qu, G. H. Liu, Chemical screen identifies a geroprotective role of quercetin in premature aging. Protein \& cell 10, 417-435 (2019); published online EpubJun (10.1007/s13238-018-0567-y).

24. Y. Li, W. Zhang, L. Chang, Y. Han, L. Sun, X. Gong, H. Tang, Z. Liu, H. Deng, Y. Ye, Y. Wang, J. Li, J. Qiao, J. Qu, W. Zhang, G. H. Liu, Vitamin C alleviates aging defects in a stem cell model for Werner syndrome. Protein \& cell 7, 478-488 (2016); published online EpubJul (10.1007/s13238-016-0278-1).

25. Y. Z. W. Wang, S. Sun, W. Li, M. Song, Q. Ji, Z. Wu, Z. Liu, Y. Fan, F. Liu, J. Li, C. R. Esteban, S. Wang, Q. Zhou, J. C. I. Belmonte, W. Zhang, J. Qu, F. Tang, G.-H. Liu, A genomewide CRISPR-based screen identifies KAT7 as a driver of cellular senescence. Transl. Med 13, (2021).

26. E. J. Grow, R. A. Flynn, S. L. Chavez, N. L. Bayless, M. Wossidlo, D. J. Wesche, L. Martin, C. B. Ware, C. A. Blish, H. Y. Chang, R. A. Pera, J. Wysocka, Intrinsic retroviral reactivation in human preimplantation embryos and pluripotent cells. Nature 522, 221-225 (2015); published online EpubJun 11 (10.1038/nature14308). 
bioRxiv preprint doi: https://doi.org/10.1101/2021.02.22.432260; this version posted February 22,2021 . The copyright holder for this preprint (which was not certified by peer review) is the author/funder, who has granted bioRxiv a license to display the preprint in perpetuity. It is made available under aCC-BY-NC-ND 4.0 International license.

27. J. D. Robin, F. Magdinier, Physiological and Pathological Aging Affects Chromatin Dynamics, Structure and Function at the Nuclear Edge. Frontiers in genetics 7, 153 (2016)10.3389/fgene.2016.00153).

28. R. Contreras-Galindo, M. H. Kaplan, P. Leissner, T. Verjat, I. Ferlenghi, F. Bagnoli, F. Giusti, M. H. Dosik, D. F. Hayes, S. D. Gitlin, D. M. Markovitz, Human endogenous retrovirus K (HML-2) elements in the plasma of people with lymphoma and breast cancer. Journal of virology 82, 9329-9336 (2008); published online EpubOct (10.1128/JVI.00646-08).

29. J. Gates, E. Killackey, L. Phillips, M. Álvarez-Jiménez, Mental health starts with physical health: current status and future directions of non-pharmacological interventions to improve physical health in first-episode psychosis. The Lancet Psychiatry 2, 726-742 (2015); published online Epub2015/08/01/ (https://doi.org/10.1016/S2215-0366(15)00213-8).

30. M. Li, L. Radvanyi, B. Yin, K. Rycaj, J. Li, R. Chivukula, K. Lin, Y. Lu, J. Shen, D. Z. Chang, D. Li, G. L. Johanning, F. Wang-Johanning, Downregulation of Human Endogenous Retrovirus Type K (HERV-K) Viral env RNA in Pancreatic Cancer Cells Decreases Cell Proliferation and Tumor Growth. Clinical cancer research : an official journal of the American Association for Cancer Research 23, $5892-5911$ (2017); published online EpubOct 1 (10.1158/1078-0432.CCR-17-0001).

31. D. Roulois, H. Loo Yau, R. Singhania, Y. Wang, A. Danesh, S. Y. Shen, H. Han, G. Liang, P. A. Jones, T. J. Pugh, C. O'Brien, D. D. De Carvalho, DNA-Demethylating Agents Target Colorectal Cancer Cells by Inducing Viral Mimicry by Endogenous Transcripts. Cell 162, 961-973 (2015); published online EpubAug 27 (10.1016/j.cell.2015.07.056).

32. K. B. Chiappinelli, P. L. Strissel, A. Desrichard, H. Li, C. Henke, B. Akman, A. Hein, N. S. Rote, L. M. Cope, A. Snyder, V. Makarov, S. Budhu, D. J. Slamon, J. D. Wolchok, D. M. Pardoll, M. W. Beckmann, C. A. Zahnow, T. Merghoub, T. A. Chan, S. B. Baylin, R. Strick, Inhibiting DNA Methylation Causes an Interferon Response in Cancer via dsRNA Including Endogenous Retroviruses. Cell 169, 361 (2017); published online EpubApr 6 (10.1016/j.cell.2017.03.036).

33. J. W. Schoggins, D. A. MacDuff, N. Imanaka, M. D. Gainey, B. Shrestha, J. L. Eitson, K. B. Mar, R. B. Richardson, A. V. Ratushny, V. Litvak, R. Dabelic, B. Manicassamy, J. D. Aitchison, A. Aderem, R. M. Elliott, A. Garcia-Sastre, V. Racaniello, E. J. Snijder, W. M. Yokoyama, M. S. Diamond, H. W. Virgin, C. M. Rice, Pan-viral specificity of IFN-induced genes reveals new roles for cGAS in innate immunity. Nature 505, 691-695 (2014); published online EpubJan 30 (10.1038/nature12862).

34. R. B. Seth, L. Sun, C. K. Ea, Z. J. Chen, Identification and characterization of MAVS, a mitochondrial antiviral signaling protein that activates NF-kappaB and IRF 3. Cell 122, 669682 (2005); published online EpubSep 9 (10.1016/j.cell.2005.08.012).

35. A. Takahashi, T. M. Loo, R. Okada, F. Kamachi, Y. Watanabe, M. Wakita, S. Watanabe, S. Kawamoto, K. Miyata, G. N. Barber, N. Ohtani, E. Hara, Downregulation of cytoplasmic DNases is implicated in cytoplasmic DNA accumulation and SASP in senescent cells. Nature communications 9, 1249 (2018); published online EpubMar 28 (10.1038/s41467-018-035558).

36. S. Watanabe, S. Kawamoto, N. Ohtani, E. Hara, Impact of senescence-associated secretory phenotype and its potential as a therapeutic target for senescence-associated diseases. Cancer science 108, 563-569 (2017); published online EpubApr (10.1111/cas.13184).

37. R. Contreras-Galindo, M. H. Kaplan, D. Dube, M. J. Gonzalez-Hernandez, S. Chan, F. Meng, M. Dai, G. S. Omenn, S. D. Gitlin, D. M. Markovitz, Human Endogenous Retrovirus Type K (HERV-K) Particles Package and Transmit HERV-K-Related Sequences. Journal of virology 89, 7187-7201 (2015)10.1128/jvi.00544-15).

38. Q. Tan, The sex chromosomes of the aging epigenome. Aging 12, 16667-16668 (2020); published online EpubAug 30 (10.18632/aging.104033).

39. T. Wang, M. Medynets, K. R. Johnson, T. T. Doucet-O'Hare, B. DiSanza, W. Li, Y. Xu, A. Bagnell, R. Tyagi, K. Sampson, N. Malik, J. Steiner, A. Hadegan, J. Kowalak, J. O'Malley, D. Maric, A. Nath, Regulation of stem cell function and neuronal differentiation by HERV-K via mTOR pathway. Proceedings of the National Academy of Sciences of the United States of America 117, 17842-17853 (2020); published online EpubJul 28 (10.1073/pnas.2002427117). 
bioRxiv preprint doi: https://doi.org/10.1101/2021.02.22.432260; this version posted February 22, 2021. The copyright holder for this preprint (which was not certified by peer review) is the author/funder, who has granted bioRxiv a license to display the preprint in perpetuity. It is made available under aCC-BY-NC-ND 4.0 International license.

40. P. Wang, Z. Liu, X. Zhang, J. Li, L. Sun, Z. Ju, J. Li, P. Chan, G. H. Liu, W. Zhang, M. Song, J. Qu, CRISPR/Cas9-mediated gene knockout reveals a guardian role of NF-kappaB/RelA in maintaining the homeostasis of human vascular cells. Protein \& cell 9, 945-965 (2018); published online EpubNov (10.1007/s13238-018-0560-5).

41. F. Wang, W. Zhang, Q. Yang, Y. Kang, Y. Fan, J. Wei, Z. Liu, S. Dai, H. Li, Z. Li, L. Xu, C. Chu, J. Qu, C. Si, W. Ji, G. H. Liu, C. Long, Y. Niu, Generation of a Hutchinson-Gilford progeria syndrome monkey model by base editing. Protein \& cell, (2020); published online EpubJul 29 (10.1007/s13238-020-00740-8).

42. H. S. Kim, O. Takenaka, T. J. Crow, Isolation and phylogeny of endogenous retrovirus sequences belonging to the HERV-W family in primates. The Journal of general virology $\mathbf{8 0}$ ( Pt 10), 2613-2619 (1999); published online EpubOct (10.1099/0022-1317-80-10-2613).

43. C. Liang, Z. Liu, M. Song, W. Li, Z. Wu, Z. Wang, Q. Wang, S. Wang, K. Yan, L. Sun, T. Hishida, Y. Cai, J. C. I. Belmonte, P. Guillen, P. Chan, Q. Zhou, W. Zhang, J. Qu, G. H. Liu, Stabilization of heterochromatin by CLOCK promotes stem cell rejuvenation and cartilage regeneration. Cell research, (2020); published online EpubJul 31 (10.1038/s41422-020-03857).

44. X. Ren, B. Hu, M. Song, Z. Ding, Y. Dang, Z. Liu, W. Zhang, Q. Ji, R. Ren, J. Ding, P. Chan, C. Jiang, K. Ye, J. Qu, F. Tang, G. H. Liu, Maintenance of Nucleolar Homeostasis by CBX4 Alleviates Senescence and Osteoarthritis. Cell reports 26, 3643-3656 e3647 (2019); published online EpubMar 26 (10.1016/j.celrep.2019.02.088).

45. L. Deng, R. Ren, Z. Liu, M. Song, J. Li, Z. Wu, X. Ren, L. Fu, W. Li, W. Zhang, P. Guillen, J. C. Izpisua Belmonte, P. Chan, J. Qu, G. H. Liu, Stabilizing heterochromatin by DGCR8 alleviates senescence and osteoarthritis. Nature communications 10, 3329 (2019); published online EpubJul 26 (10.1038/s41467-019-10831-8).

46. L. Fu, Y. Hu, M. Song, Z. Liu, W. Zhang, F. X. Yu, J. Wu, S. Wang, J. C. Izpisua Belmonte, P. Chan, J. Qu, F. Tang, G. H. Liu, Up-regulation of FOXD1 by YAP alleviates senescence and osteoarthritis. PLoS biology 17, e3000201 (2019); published online EpubApr (10.1371/journal.pbio.3000201).

47. G. Mameli, G. L. Erre, E. Caggiu, S. Mura, D. Cossu, M. Bo, M. L. Cadoni, A. Piras, N. Mundula, E. Colombo, G. Buscetta, G. Passiu, L. A. Sechi, Identification of a HERV-K env surface peptide highly recognized in Rheumatoid Arthritis (RA) patients: a cross-sectional case-control study. Clinical and experimental immunology 189, 127-131 (2017); published online EpubJul (10.1111/cei.12964).

48. B. A. Nexo, P. Villesen, K. K. Nissen, H. M. Lindegaard, P. Rossing, T. Petersen, L. Tarnow, B. Hansen, T. Lorenzen, K. Horslev-Petersen, S. B. Jensen, S. Bahrami, M. Lajer, K. L. Schmidt, H. H. Parving, P. Junker, M. J. Laska, Are human endogenous retroviruses triggers of autoimmune diseases? Unveiling associations of three diseases and viral loci. Immunologic research 64, 55-63 (2016); published online EpubFeb (10.1007/s12026-015-8671-z).

49. G. Freimanis, P. Hooley, H. D. Ejtehadi, H. A. Ali, A. Veitch, P. B. Rylance, A. Alawi, J. Axford, A. Nevill, P. G. Murray, P. N. Nelson, A role for human endogenous retrovirus-K (HML-2) in rheumatoid arthritis: investigating mechanisms of pathogenesis. Clinical and experimental immunology 160, 340-347 (2010); published online EpubJun (10.1111/j.13652249.2010.04110.x).

50. R. Douville, J. Liu, J. Rothstein, A. Nath, Identification of active loci of a human endogenous retrovirus in neurons of patients with amyotrophic lateral sclerosis. Annals of neurology $\mathbf{6 9}$, 141-151 (2011); published online EpubJan (10.1002/ana.22149).

51. C. A. Dendrou, L. Fugger, M. A. Friese, Immunopathology of multiple sclerosis. Nature reviews. Immunology 15, 545-558 (2015); published online EpubSep 15 (10.1038/nri3871).

52. R. Sankowski, J. J. Strohl, T. S. Huerta, E. Nasiri, A. N. Mazzarello, C. D'Abramo, K. F. Cheng, O. Staszewski, M. Prinz, P. T. Huerta, Y. Al-Abed, Endogenous retroviruses are associated with hippocampus-based memory impairment. Proceedings of the National Academy of Sciences of the United States of America 116, 25982-25990 (2019); published online EpubDec 17 (10.1073/pnas.1822164116).

53. W. Barbot, A. Dupressoir, V. Lazar, T. Heidmann, Epigenetic regulation of an IAP retrotransposon in the aging mouse: progressive demethylation and de-silencing of the 
bioRxiv preprint doi: https://doi.org/10.1101/2021.02.22.432260; this version posted February 22, 2021. The copyright holder for this preprint (which was not certified by peer review) is the author/funder, who has granted bioRxiv a license to display the preprint in perpetuity. It is made available under aCC-BY-NC-ND 4.0 International license.

element by its repetitive induction. Nucleic acids research 30, 2365-2373 (2002); published online EpubJun 1 (10.1093/nar/30.11.2365).

54. E. Balestrieri, F. Pica, C. Matteucci, R. Zenobi, R. Sorrentino, A. Argaw-Denboba, C. Cipriani, I. Bucci, P. Sinibaldi-Vallebona, Transcriptional activity of human endogenous retroviruses in human peripheral blood mononuclear cells. BioMed research international 2015, 164529 (2015)10.1155/2015/164529).

55. K. Bieda, A. Hoffmann, K. Boller, Phenotypic heterogeneity of human endogenous retrovirus particles produced by teratocarcinoma cell lines. The Journal of general virology 82, 591-596 (2001); published online EpubMar (10.1099/0022-1317-82-3-591).

56. B. Min, K. Jeon, J. S. Park, Y. K. Kang, Demethylation and derepression of genomic retroelements in the skeletal muscles of aged mice. Aging cell 18, e13042 (2019); published online EpubDec (10.1111/acel.13042).

57. M. Simon, M. Van Meter, J. Ablaeva, Z. Ke, R. S. Gonzalez, T. Taguchi, M. De Cecco, K. I. Leonova, V. Kogan, S. L. Helfand, N. Neretti, A. Roichman, H. Y. Cohen, M. V. Meer, V. N. Gladyshev, M. P. Antoch, A. V. Gudkov, J. M. Sedivy, A. Seluanov, V. Gorbunova, LINE1 Derepression in Aged Wild-Type and SIRT6-Deficient Mice Drives Inflammation. Cell Metabolism 29, 871-885.e875 (2019); published online Epub2019/04/02/ (https://doi.org/10.1016/j.cmet.2019.02.014).

58. M. De Cecco, T. Ito, A. P. Petrashen, A. E. Elias, N. J. Skvir, S. W. Criscione, A. Caligiana, G. Brocculi, E. M. Adney, J. D. Boeke, O. Le, C. Beauséjour, J. Ambati, K. Ambati, M. Simon, A. Seluanov, V. Gorbunova, P. E. Slagboom, S. L. Helfand, N. Neretti, J. M. Sedivy, L1 drives IFN in senescent cells and promotes age-associated inflammation. Nature 566, 73-78 (2019); published online Epub2019/02/01 (10.1038/s41586-018-0784-9).

59. M. Van Meter, M. Kashyap, S. Rezazadeh, A. J. Geneva, T. D. Morello, A. Seluanov, V. Gorbunova, SIRT6 represses LINE1 retrotransposons by ribosylating KAP1 but this repression fails with stress and age. Nature communications 5, 5011 (2014); published online EpubSep 23 (10.1038/ncomms6011).

60. G. Pawelec, A. Bronikowski, S. C. Cunnane, L. Ferrucci, C. Franceschi, T. Fulop, P. Gaudreau, V. N. Gladyshev, E. S. Gonos, V. Gorbunova, B. K. Kennedy, A. Larbi, J. F. Lemaitre, G. H. Liu, A. B. Maier, J. A. Morais, O. T. Nobrega, A. Moskalev, M. O. Rikkert, A. Seluanov, A. M. Senior, S. Ukraintseva, Q. Vanhaelen, J. Witkowski, A. A. Cohen, The conundrum of human immune system "senescence". Mechanisms of ageing and development 192, 111357 (2020); published online EpubDec (10.1016/j.mad.2020.111357).

61. M. Zhang, J. Q. Liang, S. Zheng, Expressional activation and functional roles of human endogenous retroviruses in cancers. Reviews in medical virology 29, e2025 (2019); published online EpubMar (10.1002/rmv.2025).

62. I. M. Campbell, T. Gambin, P. Dittwald, C. R. Beck, A. Shuvarikov, P. Hixson, A. Patel, A. Gambin, C. A. Shaw, J. A. Rosenfeld, P. Stankiewicz, Human endogenous retroviral elements promote genome instability via non-allelic homologous recombination. BMC biology 12, 74 (2014); published online EpubSep 23 (10.1186/s12915-014-0074-4).

63. R. Tyagi, W. Li, D. Parades, M. A. Bianchet, A. Nath, Inhibition of human endogenous retrovirus-K by antiretroviral drugs. Retrovirology 14, 21 (2017); published online EpubMar 22 (10.1186/s12977-017-0347-4).

64. F. Wang-Johanning, K. Rycaj, J. B. Plummer, M. Li, B. Yin, K. Frerich, J. G. Garza, J. Shen, K. Lin, P. Yan, S. A. Glynn, T. H. Dorsey, K. K. Hunt, S. Ambs, G. L. Johanning, Immunotherapeutic potential of anti-human endogenous retrovirus-K envelope protein antibodies in targeting breast tumors. Journal of the National Cancer Institute 104, 189-210 (2012); published online EpubFeb 8 (10.1093/jnci/djr540).

65. J. Krishnamurthy, B. A. Rabinovich, T. Mi, K. C. Switzer, S. Olivares, S. N. Maiti, J. B. Plummer, H. Singh, P. R. Kumaresan, H. M. Huls, F. Wang-Johanning, L. J. Cooper, Genetic Engineering of T Cells to Target HERV-K, an Ancient Retrovirus on Melanoma. Clinical cancer research : an official journal of the American Association for Cancer Research 21, 3241-3251 (2015); published online EpubJul 15 (10.1158/1078-0432.CCR-14-3197).

66. S. Ma, S. Sun, J. Li, Y. Fan, J. Qu, L. Sun, S. Wang, Y. Zhang, S. Yang, Z. Liu, Z. Wu, S. Zhang, Q. Wang, A. Zheng, S. Duo, Y. Yu, J. C. I. Belmonte, P. Chan, Q. Zhou, M. Song, W. 
bioRxiv preprint doi: https://doi.org/10.1101/2021.02.22.432260; this version posted February 22,2021 . The copyright holder for this preprint (which was not certified by peer review) is the author/funder, who has granted bioRxiv a license to display the preprint in perpetuity. It is made available under aCC-BY-NC-ND 4.0 International license.

Zhang, G. H. Liu, Single-cell transcriptomic atlas of primate cardiopulmonary aging. Cell research, (2020); published online EpubSep 10 (10.1038/s41422-020-00412-6).

67. W. Zhang, S. Zhang, P. Yan, J. Ren, M. Song, J. Li, J. Lei, H. Pan, S. Wang, X. Ma, S. Ma, H. Li, F. Sun, H. Wan, W. Li, P. Chan, Q. Zhou, G. H. Liu, F. Tang, J. Qu, A single-cell transcriptomic landscape of primate arterial aging. Nature communications 11, 2202 (2020); published online EpubMay 5 (10.1038/s41467-020-15997-0).

68. S. Bi, Z. Liu, Z. Wu, Z. Wang, X. Liu, S. Wang, J. Ren, Y. Yao, W. Zhang, M. Song, G. H. Liu, J. Qu, SIRT7 antagonizes human stem cell aging as a heterochromatin stabilizer. Protein \& cell 11, 483-504 (2020); published online EpubJul (10.1007/s13238-020-00728-4).

69. Z. Zou, X. Long, Q. Zhao, Y. Zheng, M. Song, S. Ma, Y. Jing, S. Wang, Y. He, C. R. Esteban, N. Yu, J. Huang, P. Chan, T. Chen, J. C. Izpisua Belmonte, W. Zhang, J. Qu, G. H. Liu, A Single-Cell Transcriptomic Atlas of Human Skin Aging. Developmental cell, (2020); published online EpubNov 23 (10.1016/j.devcel.2020.11.002).

70. L. Balaj, R. Lessard, L. Dai, Y. J. Cho, S. L. Pomeroy, X. O. Breakefield, J. Skog, Tumour microvesicles contain retrotransposon elements and amplified oncogene sequences. Nature communications 2, 180 (2011); published online EpubFeb 1 (10.1038/ncomms1180).

71. H. Hu, Q. Ji, M. Song, J. Ren, Z. Liu, Z. Wang, X. Liu, K. Yan, J. Hu, Y. Jing, S. Wang, W. Zhang, G. H. Liu, J. Qu, ZKSCAN3 counteracts cellular senescence by stabilizing heterochromatin. Nucleic acids research 48, 6001-6018 (2020); published online EpubJun 19 (10.1093/nar/gkaa425).

72. F. Debacq-Chainiaux, J. D. Erusalimsky, J. Campisi, O. Toussaint, Protocols to detect senescence-associated beta-galactosidase (SA-betagal) activity, a biomarker of senescent cells in culture and in vivo. Nature protocols 4, 1798-1806 (2009)10.1038/nprot.2009.191).

73. K. Kaufmann, J. M. Muino, M. Osteras, L. Farinelli, P. Krajewski, G. C. Angenent, Chromatin immunoprecipitation (ChIP) of plant transcription factors followed by sequencing (ChIP-SEQ) or hybridization to whole genome arrays (ChIP-CHIP). Nature protocols $\mathbf{5}, 457$ 472 (2010); published online EpubMar (10.1038/nprot.2009.244).

74. H. Li, Z. Wu, X. Liu, S. Zhang, Q. Ji, X. Jiang, Z. Liu, S. Wang, J. Qu, W. Zhang, M. Song, E. Song, G. H. Liu, ALKBH1 deficiency leads to loss of homeostasis in human diploid somatic cells. Protein \& cell, (2020); published online EpubJul 13 (10.1007/s13238-020-00744-4).

75. L. Deng, R. Ren, Z. Liu, M. Song, J. Li, Z. Wu, X. Ren, L. Fu, W. Li, W. Zhang, Stabilizing heterochromatin by DGCR8 alleviates senescence and osteoarthritis. Nature communications 10, 1-16 (2019).

76. D. Kim, B. Langmead, S. L. Salzberg, HISAT: a fast spliced aligner with low memory requirements. Nature methods 12, 357 (2015).

77. S. Anders, P. T. Pyl, W. Huber, HTSeq-a Python framework to work with high-throughput sequencing data. Bioinformatics 31, 166-169 (2015).

78. M. I. Love, W. Huber, S. Anders, Moderated estimation of fold change and dispersion for RNA-seq data with DESeq2. Genome Biol 15, 550 (2014)10.1186/s13059-014-0550-8).

79. W. Li, W. He, P. Xia, W. Sun, M. Shi, Y. Zhou, W. Zhu, L. Zhang, B. Liu, J. Zhu, Y. Zhu, E. Zhou, M. Sun, K. Gao, Total Extracts of Abelmoschus manihot L. Attenuates AdriamycinInduced Renal Tubule Injury via Suppression of ROS-ERK1/2-Mediated NLRP3 Inflammasome Activation. Frontiers in pharmacology 10, 567 (2019)10.3389/fphar.2019.00567).

80. M. De Cecco, T. Ito, A. P. Petrashen, A. E. Elias, N. J. Skvir, S. W. Criscione, A. Caligiana, G. Brocculi, E. M. Adney, J. D. Boeke, O. Le, C. Beausejour, J. Ambati, K. Ambati, M. Simon, A. Seluanov, V. Gorbunova, P. E. Slagboom, S. L. Helfand, N. Neretti, J. M. Sedivy, L1 drives IFN in senescent cells and promotes age-associated inflammation. Nature 566, 73-78 (2019); published online EpubFeb (10.1038/s41586-018-0784-9).

81. A. Subramanian, H. Kuehn, J. Gould, P. Tamayo, J. P. Mesirov, GSEA-P: a desktop application for Gene Set Enrichment Analysis. Bioinformatics 23, 3251-3253 (2007); published online EpubDec 1 (10.1093/bioinformatics/btm369).

82. S. W. Criscione, Y. Zhang, W. Thompson, J. M. Sedivy, N. Neretti, Transcriptional landscape of repetitive elements in normal and cancer human cells. BMC genomics 15, 583 (2014). 
bioRxiv preprint doi: https://doi.org/10.1101/2021.02.22.432260; this version posted February 22, 2021. The copyright holder for this preprint (which was not certified by peer review) is the author/funder, who has granted bioRxiv a license to display the preprint in perpetuity. It is made available under aCC-BY-NC-ND 4.0 International license.

83. M. D. Robinson, D. J. McCarthy, G. K. Smyth, edgeR: a Bioconductor package for differential expression analysis of digital gene expression data. Bioinformatics 26, 139-140 (2010).

84. D. F. Grabski, A. Ratan, L. R. Gray, S. Bekiranov, D. Rekosh, M. L. Hammarskjold, S. K. Rasmussen, Upregulation of human endogenous retrovirus-K (HML-2) mRNAs in hepatoblastoma: Identification of potential new immunotherapeutic targets and biomarkers. $J$ Pediatr Surg, (2020); published online EpubMay 27 (10.1016/j.jpedsurg.2020.05.022).

85. R. P. Subramanian, J. H. Wildschutte, C. Russo, J. M. Coffin, Identification, characterization, and comparative genomic distribution of the HERV-K (HML-2) group of human endogenous retroviruses. Retrovirology 8, 90 (2011); published online EpubNov 8 (10.1186/1742-4690-890).

86. R. Patro, G. Duggal, M. I. Love, R. A. Irizarry, C. Kingsford, Salmon provides fast and biasaware quantification of transcript expression. Nat Methods 14, 417-419 (2017); published online EpubApr (10.1038/nmeth.4197).

87. H. Thorvaldsdottir, J. T. Robinson, J. P. Mesirov, Integrative Genomics Viewer (IGV): highperformance genomics data visualization and exploration. Brief Bioinform 14, 178-192 (2013); published online EpubMar (10.1093/bib/bbs017).

88. S. Chen, Y. Zhou, Y. Chen, J. Gu, fastp: an ultra-fast all-in-one FASTQ preprocessor. Bioinformatics 34, i884-i890 (2018); published online EpubSep 1 (10.1093/bioinformatics/bty560).

89. Y. Xi, W. Li, BSMAP: whole genome bisulfite sequence MAPping program. BMC Bioinformatics 10, 232 (2009); published online EpubJul 27 (10.1186/1471-2105-10-232).

\section{Acknowledgements}

We would like to thank the Center for Biological Imaging (CBI), Institute of Biophysics, Chinese Academy of Science for TEM analysis, and we would be grateful to C. Peng for TEM sample preparation and L. Zhang for the help of TEM operation. We also would like to express our gratitude to Y. Li (Tsinghua University) for immuno-TEM sample preparation and J. Hao (Institute of Biophysics) for help with image scanning. We also would like to thank Z. Zhang, Y. Tao (Spatial FISH, Co., Ltd) for the technical help in the FISH experiment. We also would like to thank L. Bai, Q. Chu, X. Zhuo, J. Lu, Y. Yang, R. Bai, and S. Ma for administrative assistance.

\section{Competing interests}

The authors declare no competing interest. 


\section{Materials and Methods}

\section{Cell culture}

HEK293T cells were cultured in Dulbecco's Modified Eagle Medium (DMEM, Thermo Fisher Scientific) supplemented with 10\% fetal bovine serum (FBS, Gibco, Thermo Fisher Scientific), 2 mmol/L GlutaMAX (Thermo Fisher Scientific), $0.1 \mathrm{mmol} / \mathrm{L}$ non-essential amino acids (NEAA, Thermo Fisher Scientific), 1\% penicillin/streptomycin (Thermo Fisher Scientific). Human MPCs (hMPCs) were grown on $0.1 \%$ gelatin (Sigma Aldrich)-coated plates (CORNING) in hMPC culture medium containing 90\% MEM Alpha Medium (Thermo Fisher Scientific), 10\% FBS, 2 mmol/L GlutaMAX, $0.1 \mathrm{mmol} / \mathrm{L}$ NEEA, $1 \%$ penicillin/streptomycin and $1 \mathrm{ng} / \mathrm{mL}$ bFGF2 (Joint Protein Central). Cells were cultured in an incubator (Thermo Fisher Scientific) at $37^{\circ} \mathrm{C}$ with $5 \% \mathrm{CO}_{2}$.

\section{Western blotting}

Cells were lysed and boiled at $105^{\circ} \mathrm{C}$ for $10 \mathrm{~min}$. Protein concentration was measured with the $\mathrm{BCA}$ Kit. Cell lysates were subjected to SDS-PAGE electrophoresis and electrotransferred onto PVDF membranes (Millipore). Membranes were incubated with primary antibodies and HRP-conjugated secondary antibodies and then blotted with substrates or Super Signal West Femto Maximum Sensitivity Substrate (Thermo Fisher Scientific). Imaging was performed with the Image Lab software. Quantification was performed by ImageJ.

\section{DNA / RNA isolation and (reverse transcription-) quantitative PCR ((RT-)qPCR)}

Total genome DNA from cells was extracted using the DNA extraction Kit following the manufacturer's instructions for qPCR. Total cell RNA was extracted in TRIzol and reverse transcribed to cDNA using GoScript Reverse Transcription System for RT-qPCR. RT-qPCR was performed using THUNDERBIRD qPCR Mix and the CFX384 Real-Time System (Bio-Rad Laboratories, Inc.). RNA was extracted from medium using the QIAamp viral RNA mini Kit (Qiagen) following the manufacturer's instructions.

\section{Droplet digital PCR (ddPCR)}

Briefly, $20 \mu \mathrm{L}$ reaction solution containing templates, primers and QX200 ddPCR EvaGreen Supermix (Bio-Rad Laboratories, Inc.) was mixed with $70 \mu \mathrm{L}$ DG Oil (Bio-Rad Laboratories, Inc.) in a DG8 cartridge (Bio-Rad Laboratories, Inc.) by QX200 droplet generator (Bio-Rad Laboratories, Inc.). The droplet was transferred to a 96 well plate and sealed with PX1 ${ }^{\text {TM }}$ PCR Plate Sealer (Bio-Rad Laboratories, Inc.). PCR amplification was carried out in a thermal cycler (Bio-Rad Laboratories, Inc.) and the sample was subsequently subjected to QX200 droplet reader (Bio-Rad Laboratories, Inc.) to analyze the absolute copy number of HERVK in the medium. 


\section{ELISA}

For the IL6 ELISA assay, medium was incubated in an IL6 antibody-coated plate which has been precoated at $4{ }^{\circ} \mathrm{C}$ overnight according to the manufacturer's instructions. The plate was then incubated with a detection antibody, Avidin-HRP and freshly mixed TMB substrate. After adding stop solution, the plate was measured at $450 \mathrm{~nm}$. To measure HERVK-Env protein levels in medium or serum, medium or human serum was tested with the Human HERVK_7p22.1 Provirus Ancestral Env Polypretein (ERVK6) ELISA Kit following the manufacturer's instructions. 2'3'-cGAMP ELISA Kit was used to measure the levels of 2'3'-cGAMP in cells.

\section{Immunofluorescence, immunohistochemistry staining and microscopy}

Cells seeded on coverslips were washed twice with PBS, fixed in 4\% paraformaldehyde (PFA), permeabilized in $0.4 \%$ Triton X-100 in PBS and blocked with $10 \%$ donkey serum. Coverslips were incubated with primary antibodies in blocking buffer at $4{ }^{\circ} \mathrm{C}$ overnight and secondary antibodies for 1 $\mathrm{hr}$ at room temperature. Nuclei were labeled by Hoechst 33342. Immunohistochemistry staining of tissue sections was performed using the DAB Staining Kit according to the manufacturer's instructions. Images were taken with a Leica SP5 confocal microscope or LEICA Aperio CS2.

\section{RNA / DNA-FISH}

For RNA-FISH, cells seeded on coverslips were fixed in fresh $4 \%$ formaldehyde solution, permeabilized and digested. Probe HERVK Alexa Fluor 488 was added to wells for $3 \mathrm{hr}$ at $41+1{ }^{\circ} \mathrm{C}$ in a HB-1000 Hybridizer. Coverslips were incubated with amplification probes. Nuclei were labeled with DAPI solution and slides were mounted and subjected to Leica SP5 confocal microscope. The DNA of HERVK gene was detected by single molecule FISH. The senescent cells were sequentially treated with RNase A and fixed. The cells were then incubated with HERVK- or ACTIN-specific probe pairs in hybridization buffer. After three washes, the cells were incubated with amplification probes and a fluorescent probe for the single-molecule detection of HERVK DNA. Finally, the cells were counterstained with DAPI and imaged by confocal microscopy.

\section{Transmission electron microscopy (TEM)}

Cells were pelleted and fixed with 2.5\% (vol/vol) glutaraldehyde with Phosphate Buffer (PB) (0.1 M, $\mathrm{pH}$ 7.4) at room temperature for $20 \mathrm{~min}$ and then at $4{ }^{\circ} \mathrm{C}$ overnight. Routine heavy metal staining was conducted. For Immuno-TEM, cells seeded in $35 \mathrm{~mm}$ petri dishes (CORNING) were fixed. Samples were dehydrated through an ethanol gradient, infiltrated and embedded in LR Gold resin containing initiator. Samples were then polymerized by UV light and sectioned using Leica EM UC7. For staining, sections were blocked at $2 \%$ BSA, incubated with anti-HERVK-Env. After washing, samples were incubated with gold-labelled anti-mouse secondary antibody, then fixed by $1 \%$ glutaraldehyde in 
$\mathrm{ddH}_{2} \mathrm{O}$. After washing, sections were stained by $2 \%$ uranyl acetate before imaged using a TEM Spirit 120 kV (FEI Tecnai Spirit 120 kV).

\section{Plasmid construction}

To generate HERVK knockdown vectors, specific shRNAs were cloned into MluI / ClaI sites of lentivirus vector pLVTHM plasmids (addgene \#12247). For activating endogenous HERVK, lentiviral constructs for NTC or HERVK LTR targeting sgRNA were cloned into lenti-SAM v2 (addgene \#75112) by ESP3I site and was co-transfected with lenti-MPH v2 (addgene \#89308).

\section{Lentivirus production}

To package lentiviral constructs, HEK293T cells were transfected with lentiviral vectors together with the packaging plasmids pMD2.G (addgene, \#12260) and psPAX2 (addgene, \#12259) using lipofectamine 3000 (Invitrogen). Supernatants containing lentivirus were harvested at $48 \mathrm{hr}$ and $72 \mathrm{hr}$ after transfection, filtered with a $0.2 \mu \mathrm{m}$ filter, concentrated by ultracentrifugation at 19,400 rpm for $2.5 \mathrm{hr}$. The virus pellets were suspended and assessed for viral titers.

\section{Cell treatment}

For lentivirus transduction, hMPCs were seeded (P0 post treatment) and incubated with lentivirus in the presence of polybrene for $24 \mathrm{hr}$. After two passages, cells were processed for SA- $\beta$-gal staining and RNA / DNA extraction. For conditioned medium treatment, $50 \%$ conditioned medium $+50 \%$ fresh medium were used for culturing early passage WT hMPCs in the presence of polybrene. The cells were passaged and used for SA- $\beta$-gal staining and RNA / DNA extraction.

\section{SA- $\beta$-gal staining}

SA- $\beta$-gal staining was performed as described previously $(22,72)$. In brief, cells were fixed with a buffer containing $2 \%(\mathrm{w} / \mathrm{v})$ formaldehyde and $0.2 \%(\mathrm{w} / \mathrm{v})$ glutaraldehyde for $5 \mathrm{~min}$ and treated with staining buffer containing $1 \mathrm{mg} / \mathrm{mL} \mathrm{X}$-gal at $37^{\circ} \mathrm{C}$ overnight. Optical microscope was used to observe stained cells and the percentage of positive cells was analyzed by ImageJ software.

\section{ChIP-qPCR}

ChIP-qPCR was performed as previously described with slight modifications (73). Briefly, cells were fixed in $1 \%$ formaldehyde in PBS and then quenched by $125 \mathrm{mM}$ Glycine. Cells were lysed on ice for $10 \mathrm{~min}$ and subjected to sonication using Covaris S220. The collected supernatants were incubated with Dynabeads Protein A pre-conjuncted with indicated antibodies. After washing, samples were digested by protease K (New England Biolabs), eluted and cross-link-reversed. DNA was extracted using Phenol-chloroform-isoamylalcohol and the eluted DNA was subjected to qPCR analysis. For immunoprecipitation of cGAS, the cytoplasmic fractions of cells was extracted after fixation (57), 
which was incubated with cGAS antibody and Dynabeads Protein A at $4{ }^{\circ} \mathrm{C}$ overnight. The DNA extraction was performed as above.

\section{RNA-seq library construction and sequencing}

RNA-seq libraries were prepared and sequenced as previously reported (74). In brief, total RNA was extracted from $1 \times 10^{6}$ cells per duplicate using TRIzol reagents, genomic DNA was removed and mRNA was isolated. Then, library preparation, quality control and high-throughput sequencing were conducted by Novogene Bioinformatics Technology Co. Ltd. For library construction, NEBNext Ultra RNA Library Prep Kit for Illumina (NEB) was used according to the manufacturer's directions. Highthroughput sequencing was performed on HiSeq X Ten platforms according to the manufacturer's instruction.

\section{RNA-seq data processing and analysis of expression level of repetitive elements}

The processing pipeline for RNA-seq data has been reported previously $(67,75)$. Pair-end raw reads were trimmed by the TrimGalore (version 0.4.5) (Babraham Bioinformatics) (https://github.com/FelixKrueger/TrimGalore) and mapped to human (Homo sapiens) hg19 reference genome obtained from UCSC genome browser database using hisat2 (version 2.0.4) (76). High quality mapped reads (score of mapping quality more than 20) were then used for counting the reads that mapped to each gene by HTSeq (version 0.11.0) (77). To evaluate expression levels of repetitive elements, the Repenrich2 pipeline was implemented (82).

\section{Whole genome bisulfite sequencing library construction and sequencing}

Library preparation and sequencing were performed as previously reported (67). In brief, genomic DNA was extracted from $2 \times 10^{6}$ cells per duplicate using DNeasy Blood \& Tissue Kits (QIAGEN) and sheared to 100-300 bp with a sonicator. Then, library preparation, bisulfite treatment, quality control and sequencing were conducted by Novogene Bioinformatics Technology Co. Ltd.

\section{Whole genome bisulfite sequencing data processing}

WGBS data analysis was performed as previously reported (67). In brief, raw sequencing reads were trimmed by fastp software (version 0.19.10) with default parameters (88). Then, cleaned reads were mapped to human (Homo sapiens) hg19 reference genome obtained from UCSC genome browser database using bsmap (version 2.90) with parameters “-v 0.1 -g 1 -R -u” (89). CpG DNA methylation levels for each cytosine site were calculated by the methratio program provided by bsmap. To ensure the accuracy of methylation level detection, forward and reverse strand reads for each $\mathrm{CpG}$ site were combined and only $\mathrm{CpG}$ sites with depth of more than 5 were kept for downstream analysis. 
bioRxiv preprint doi: https://doi.org/10.1101/2021.02.22.432260; this version posted February 22, 2021. The copyright holder for this preprint (which was not certified by peer review) is the author/funder, who has granted bioRxiv a license to display the preprint in perpetuity. It is made available under aCC-BY-NC-ND 4.0 International license.

All data were statistically analyzed using the PRISM version 8 software (GraphPad Software). Results were presented as mean \pm SEM. Comparisons were conducted using the two-tailed student's $t$ test and one-way ANOVA. $P$ values $<0.05$ were considered statistically significant $(*), P$ values $<0.01$ were considered highly statistically significant $(* *)$ and $P$ values $<0.001$ were considered highly statistically significant $(* * *)$. 
bioRxiv preprint doi: https://doi.org/10.1101/2021.02.22.432260; this version posted February 22, 2021. The copyright holder for this preprint (which was not certified by peer review) is the author/funder, who has granted bioRxiv a license to display the preprint in perpetuity. It is made available under aCC-BY-NC-ND 4.0 International license.

\section{Figure legends}

Fig. 1. Epigenetic derepression of HERVK and virus-like particles are observed in prematurely aged hMPCs.

(A) Left: Schematic diagram of replicative senescent (RS) and premature aging models of hMPCs. Top, WT hMPCs which are replicative senescent in their late passage (LP, P>12); middle and bottom, premature aging HGPS $\left(L M N A^{\mathrm{G} 608 \mathrm{G} /+}\right)$ and WS $\left(W R N^{-/}\right)$hMPCs models, respectively, constructed via genome-editing in human embryonic stem cells (hESCs) followed by direct differentiation to hMPCs and exhibiting growth arrest at passage 8-9 (referred to LP for premature aging model) (22). Right: Schematic diagram of the HERVK proviral genome structure flanked by human-specific LTR5HS insertions and internal coding protein sequences (HERVK-Int). HERVK retroviral elements are able to transcribe, translate, package into retrovirus-like particles (RVLPs). Gag, group-specific antigen; Pro, protease; Pol, polymerase; Env, envelope. (B) Left: Ring plot showing the composition of shared upregulated repetitive elements (REs) in premature aging and RS hMPCs as categorized in each repetitive element class. REs upregulated in at least three comparisons are taken into consideration. Right: Family enrichment analysis for the shared upregulated REs of LTR class in premature aging and RS hMPCs. (C) Left: Genome browser view of the RNA levels (reads per kilobase of bin per million of reads, RPKM) of HML2 in WT and premature aging hMPCs at early passage (EP, P3) and late passage (LP, P9). Right: Box plot showing quantitative analysis of HML2 expression levels (transcripts per kilobase million, TPM) in RS (WT EP vs. LP) and premature aging hMPCs. $* P<0.05$, $* * P<0.01, * * * P<0.001$ ( $t$ test). (D) Heatmap showing the levels of HERVK transcripts covering env, pol and gag regions, as well as senescence markers genes in WT, HGPS, and WS hMPCs at EP and LP by RT-qPCR. 4 wells per condition. (E) Left: Representative images of HERVK RNA FISH in WT, HGPS and WS hMPCs. Arrows indicate HERVK RNA signals in cytoplasm. Scale bars, $10 \mu \mathrm{m}$. Right: Quantification of HERVK RNA-FISH fluorescence intensity. Three independent experimental sets $(\mathrm{n}>50$ for each set). $* * * P<0.001$ ( $t$ test). $(\mathbf{F})$ Violin plot showing the CpG DNA methylation levels (mCG/CG) for HERVK in RS (WT EP vs. LP) and premature aging hMPCs. The white dots represent the median values, and the white lines represent the values within the interquartile range (IQR) from smallest to largest. $* P<0.05, * * * P<0.001$ ( $t$ test). (G) ChIP-qPCR assessment of H3K9me3 enrichment of HERVK-LTR5HS regions in WT, HGPS, and WS hMPCs. $n=3$, biological samples with 4 wells in each sample. Data are presented as mean \pm SEM. $* * * P<0.001$ ( $t$ test). (H) Left: Z-stack 3D reconstruction of HERVK-Env immunofluorescence staining (shown in Fig. S4A) in WT, HGPS and WS hMPCs. Scale bars, $10 \mu \mathrm{m}$. Right: Quantification of HERVK-Env fluorescence intensity. Three independent experimental sets ( $\mathrm{n}>100$ for each set). $* * * P<0.001$ ( $t$ test). (I) Left: Western blotting of HERVK-Env, p16 ${ }^{\text {INK4a }}$, LAP2 $\beta$ in WT, HGPS and WS hMPCs. GAPDH was used as the loading control. Right: Statistical analysis of the relative HERVK-Env expression. $n=3$. Data are presented as the mean \pm SEM. $* P<0.05, * * P<0.01$ ( $t$ test). $(\mathbf{J})$ Left: TEM immune-gold labelling 
of WT, HGPS and WS hMPCs using HERVK-Env antibody. Regions highlighted by white squares indicate HERVK putative RVLPs labelled with gold particles in cells. Higher magnification of the indicated regions is shown at right. Scale bars, $200 \mathrm{~nm}$ (left), $100 \mathrm{~nm}$ (right). Dashed lines label the cell membrane. E: Extracellular; I: Intracellular. Right: Statistical analysis of the number of HERVK RVLPs labelled with gold particles per cell. More than 40 cells were quantified in each group. $* * * P<$ 0.001 ( $t$ test).

Fig. 2. Increased HERVK mobilization drives cellular senescence via activation of innate immunity pathway.

(A) Schematic diagram of experimental design to investigate the role of HERVK in cellular senescence by activation or knockdown of HERVK. (B) Left: Western blotting of HERVK-Env in WT hMPCs transduced with non-targeting sgNTC or sgHERVK using a CRISPR activation system. GAPDH was used as a loading control. Right: Statistical analysis of the relative levels of HERVK-Env. $\mathrm{n}=3 . * P<0.05$ ( $t$ test). (C) Left: SA- $\beta$-gal staining of WT hMPCs transduced with non-targeting sgNTC or sgHERVK using a CRISPR activation system. Scale bars, $20 \mu \mathrm{m}$. Right: Statistical analysis of the relative percentages of SA- $\beta$-gal-positive cells. $n=3$, biological samples. Over 100 cells were quantified in each sample. ${ }^{* *} P<0.01$ ( $t$ test). (D) Left: Western blotting of HERVK-Env in prematurely senescent HGPS and WS hMPCs after transduction of lentivirus delivering shControl or shHERVK. GAPDH was used as a loading control. Right: Statistical analysis of the relative protein levels of HERVK-Env, which was normalized to respective shControl group in corresponding cell lines. $\mathrm{n}=3$. ${ }^{* *} P<0.01$ ( $t$ test). $(\mathbf{E})$ Left: SA- $\beta$-gal staining of HGPS and WS hMPCs after transduction of lentivirus delivering shControl or shHERVK. Scale bars, $20 \mu \mathrm{m}$. Right: Statistical analysis of the relative percentages of SA- $\beta$-gal-positive cells, which was normalized to respective shControl group in corresponding cell lines. $\mathrm{n}=3$, biological samples. Over 100 cells were quantified in each sample. ${ }^{*} P<0.01$ ( $t$ test). (F) Left: Representative HERVK DNA-FISH images in EP and LP of WT hMPCs. Higher magnification of indicated regions indicating fluorescent spots in the cytoplasm is shown at right. Scale bars, $10 \mu \mathrm{m}$ (left); $200 \mathrm{~nm}$ (right). Cyto: cytoplasm, Nuc: nucleus. Right: Quantification of relative number of fluorescent spots in the cytoplasm. Over 10 cells were quantified in each sample. Data are presented as the mean \pm SEM. $* * * P<0.001$ ( $t$ test). (G) Schematic diagram of the innate immune response through the cGAS-STING pathway. The viral nucleic acid DNA is detected by cGAS, which activates STING, which thereby activates TBK1, IRF3, and RelA/NF-kB (RelA) via phosphorylation, resulting in p-IRF3 and p-RelA translocation into the nucleus and transcription of SASP. (H) Immunoprecipitation assay showing assessment of cGAS binding to cytoplasmic HERVK DNA fragments in EP and LP of WT hMPCs by qPCR. $n=4$, wells in each condition. ${ }^{* *} P<0.01$ ( $t$ test). (I) ELISA analysis of 2'3'-cGAMP levels in WT, HGPS, and 
WS hMPCs. cGAMP levels were normalized to cell number. $\mathrm{n}=3$, biological samples. ${ }^{*} P<0.05$, $* * * P<0.001$ ( $t$ test). $(\mathbf{J})$ Left: Western blotting of p-TBK1, p-IRF3 and p-RelA in WT, HGPS and WS hMPCs. GAPDH was used as the loading control. Right: Statistical analysis of the relative protein levels of p-TBK1, p-IRF3 and p-RelA. $\mathrm{n}=3$. $* * P<0.01$ ( $t$ test). (K) ELISA analysis of IL6 levels in the culture medium of WT, HGPS and WS hMPCs. IL6 levels were normalized to cell number. $n=3$, biological samples. $* * * P<0.001$ ( $t$ test). (L) ELISA analysis of IL6 levels in the culture medium of HGPS and WS hMPCs after transduction of shControl or shHERVK lentivirus. IL6 levels were normalized to cell number. $\mathrm{n}=3$, biological samples. ${ }^{*} P<0.05$, $* * * P<0.001$ ( $t$ test). (M) Left: Western blotting showing the protein levels of p-TBK1, p-IRF3 and p-RelA in WT hMPCs transduced with non-targeting sgNTC or sgHERVK using a CRISPR activation system. GAPDH was used a loading control. Right: Statistical analysis of the relative levels of p-TBK1, p-IRF3 and p-RelA. $\mathrm{n}=3$. $* P<0.05$ ( $t$ test). (N) ELISA analysis of IL6 levels in the culture medium of WT hMPCs (P6) transduced with non-targeting sgNTC or sgHERVK using a CRISPR activation system. IL6 levels were normalized to cell number. $\mathrm{n}=3$, biological samples. $* * * P<0.001$ ( $t$ test $)$. All data are presented as mean $\pm \mathrm{SEM}$.

\section{Fig. 3. HERVK released by senescent cells induces senescence in young cells.}

(A) Schematic diagram of the proposed HERVK viral life cycle in senescent cells, with some RVLPs assembled intracellularly while others are budding from the cell membrane and released outside of the cells. (B) Left: Digital droplet PCR detected HERVK levels in microvesicles isolated from conditioned medium (CM) of WT, HGPS and WS hMPCs cultures. $\mathrm{ddH}_{2} \mathrm{O}$ and cDNA from aged hMPCs were used as a negative and positive control, respectively. Right: Statistical analysis of the relative RNA copy number of HERVK in the medium from the same amount of cell number of each group. $\mathrm{n}=3$, biological samples. ${ }^{*} * * P<0.001$ ( $t$ test). (C) ELISA analysis of HERVK-Env levels in the concentrated CM of WT, HGPS and WS hMPCs. HERVK-Env levels were normalized to cell number. $\mathrm{n}=3$, biological samples. ${ }^{*} P<0.01$ ( $t$ test). (D) TEM immune-gold labelling in WT, HGPS and WS hMPCs with HERVK-Env antibody. Regions highlighted by white squares indicate HERVK putative RVLPs labelled with gold particles budding from cell membranes or outside the cells. Higher magnification of the indicated regions is shown at right. Scale bars, $200 \mathrm{~nm}$ (left), $100 \mathrm{~nm}$ (right). Dashed lines label the cell membrane. E: Extracellular; I: Intracellular. (E) Schematic diagram of treatment of young hMPCs with CM from senescent cells. Cells in red and yellow color represent senescent and young cells, respectively. (F) TEM of young hMPCs treated with CM from WT or WS hMPCs. Regions highlighted by white squares indicate putative RVLPs adhering to the surface of cells. Higher magnification of the indicated regions is shown at right. Scale bars, $200 \mathrm{~nm}$ (left), $100 \mathrm{~nm}$ (right). Dashed lines label the cell membrane. E: Extracellular; I: Intracellular. (G) Heatmap showing 
the transcript levels of HERVK and senescence markers genes in young hMPCs treated with CM of WT, HGPS, WS and LP WT hMPCs by RT-qPCR. $\mathrm{n}=3$, biological samples with 4 well replicates in each set. (H) Left: SA- $\beta$-gal staining of young hMPCs (WT) treated with CM from WT, HGPS, WS and LP WT hMPCs. Scale bars, $20 \mu \mathrm{m}$. Right: Statistical analysis of the relative percentages of SA- $\beta$ gal-positive cells. $\mathrm{n}=3$, biological samples. Over 100 cells were quantified in each sample. $* * * P<$ 0.001 (one-way ANOVA). (I) Schematic diagram of HERVK depletion from the CM of senescent cells using an anti-HERVK-Env antibody. The HERVK-depleted CM was used to treat young hMPCs and the immuno-precipitates were used for western blotting. Cells in red and yellow color represent senescent and young cells, respectively. (J) Heatmap showing the levels of HERVK and senescence marker genes in young hMPCs (WT P6) treated with CM from HGPS, WS and LP WT hMPCs or HERVK-depleted counterparts by RT-qPCR. 4 wells in each condition. (K) Statistical analysis of the relative percentages of SA- $\beta$-gal-positive cells in young hMPCs (WT) treated with CM from HGPS, WS and LP WT hMPCs or HERVK-depleted counterparts. $n=3$, biological samples. Over 100 cells are quantified in each sample. ${ }^{* *} P<0.01$ (one-way ANOVA).

\section{Fig. 4. Human endogenous retrovirus functions as a biomarker of aging.}

(A) Left: Schematic diagram of primary hMPCs, skin and serum samples from young and old human donors. (B) Relative expression of HERVK in human primary MPCs from young and old donors by RT-qPCR. $\mathrm{n}=4$, number of individuals with 4 well duplicates for each individual. $* * P<0.01$, $* * * P<$ 0.001 ( $t$ test). (C) Right: Representative HERVK-Env immunohistochemistry staining in young and old human skin with higher magnification of indicated region shown. (Black boxes labelling cells in epidermis and red boxes labelling cells in derma). Scale bars, $50 \mu \mathrm{m}$ (left), $10 \mu \mathrm{m}$ (right). Right: Quantification of immunohistochemistry intensity of HERVK-Env, $n=3$, number of donors in each group. Data are presented as means \pm SEM. ${ }^{* *} P<0.01$ ( $t$ test). (D) ELISA analysis of HERVK-Env levels in serum from young and old donors. $\mathrm{n}=30$, number of donors in each group. ${ }^{* * *} P<0.001(t$ test). All data are presented as mean \pm SEM.

Fig. 5. Schematic diagram proposing a working model for how HERVK acts as a driver and biomarker in aging.

HERVK is upregulated during cellular senescence via an epigenetic derepression mechanism. An enhanced level of HERVK activates innate immune response, thereby inducing cellular senescence. HERVKs form RVLPs in senescent cells, which are released into the cultural medium and may transfer into younger cells causing their senescence in a paracrine manner. A HERVK neutralizing antibody blocks their transmissible pro-senescence effect, indicating HERVK functions as a driver of cellular senescence. Furthermore, HERVK can be detected in the blood of the elderly, suggesting that HERVK can be used as a diagnostic biomarker of human aging. 
bioRxiv preprint doi: https://doi.org/10.1101/2021.02.22.432260; this version posted February 22, 2021. The copyright holder for this

Fig. 1 preprint (which was not certified by peer review) is the author/funder, who has granted bioRxiv a license to display the preprint in A perpetuity. It is made available under aCC-BY-NC-ND 4.0 International license.

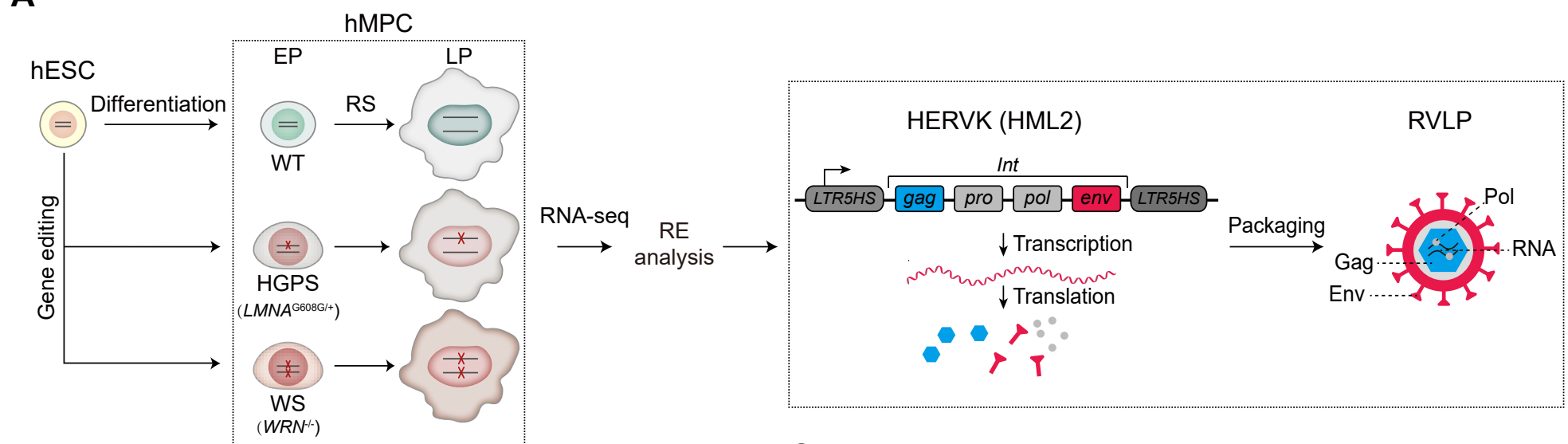

B

$\underline{\text { hMPC }}$

H

$\underline{\text { hMPC }}$

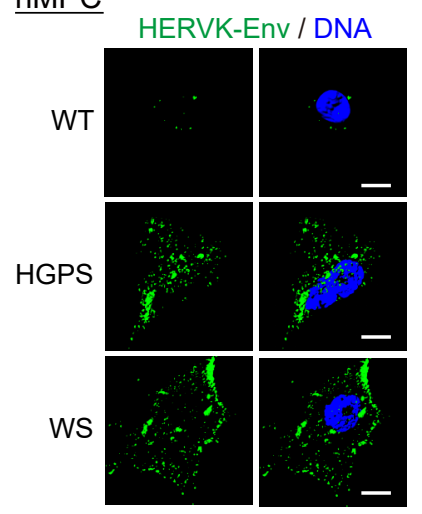

D

hMPC
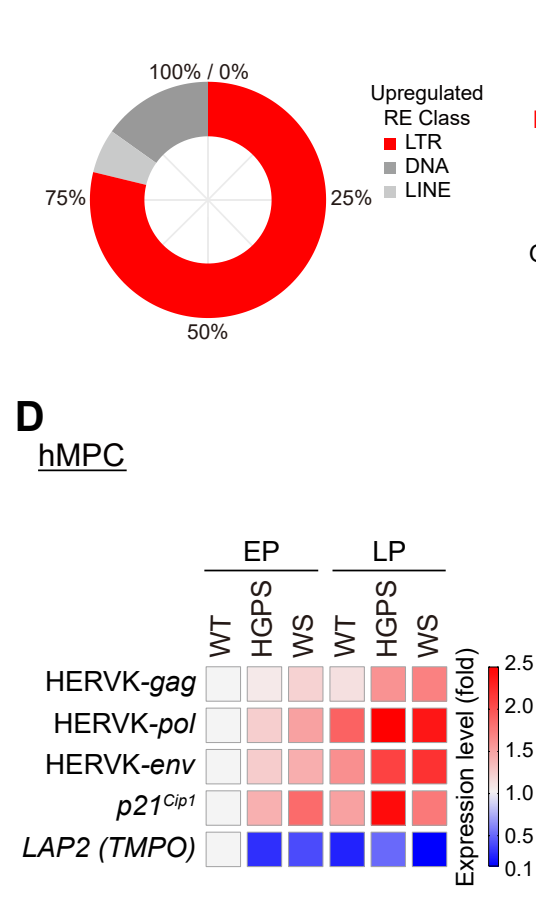

E

hMPC
C

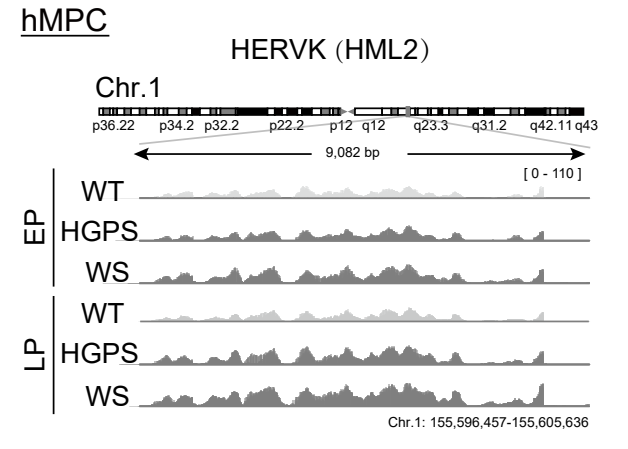

F

G

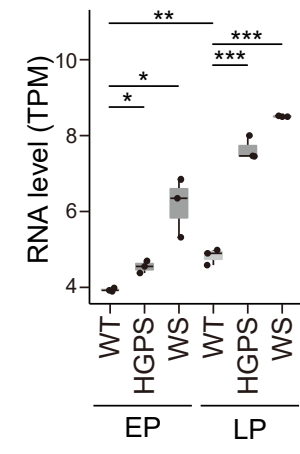
hMPC

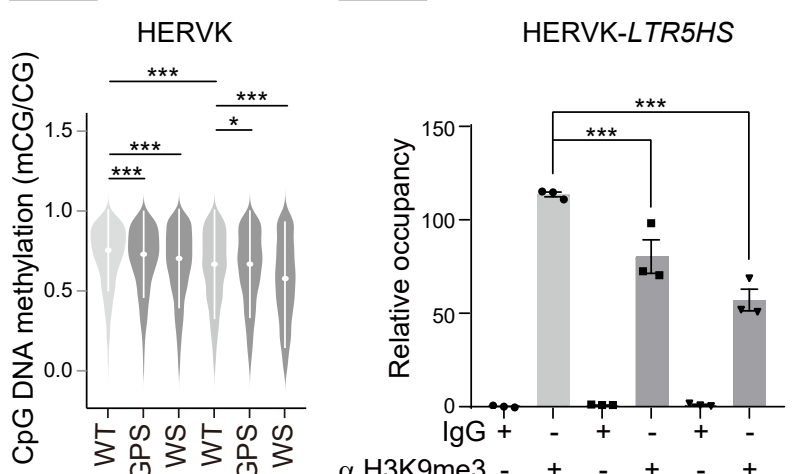

WT $\overline{\text { HGPS }} \overline{\text { WS }}$
hMPC

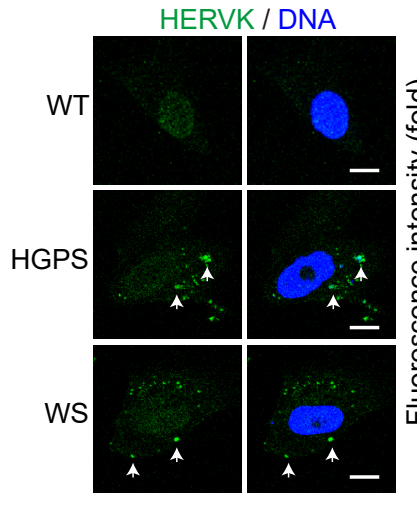

I

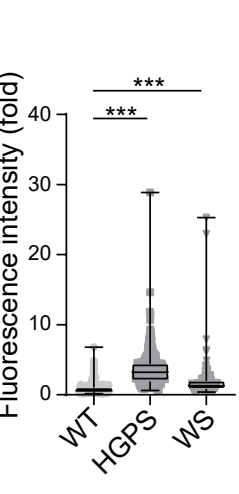

$$
\frac{{ }^{\text {T }}}{\text { J }} \frac{\text { ㅇ }}{\text { LP }}
$$
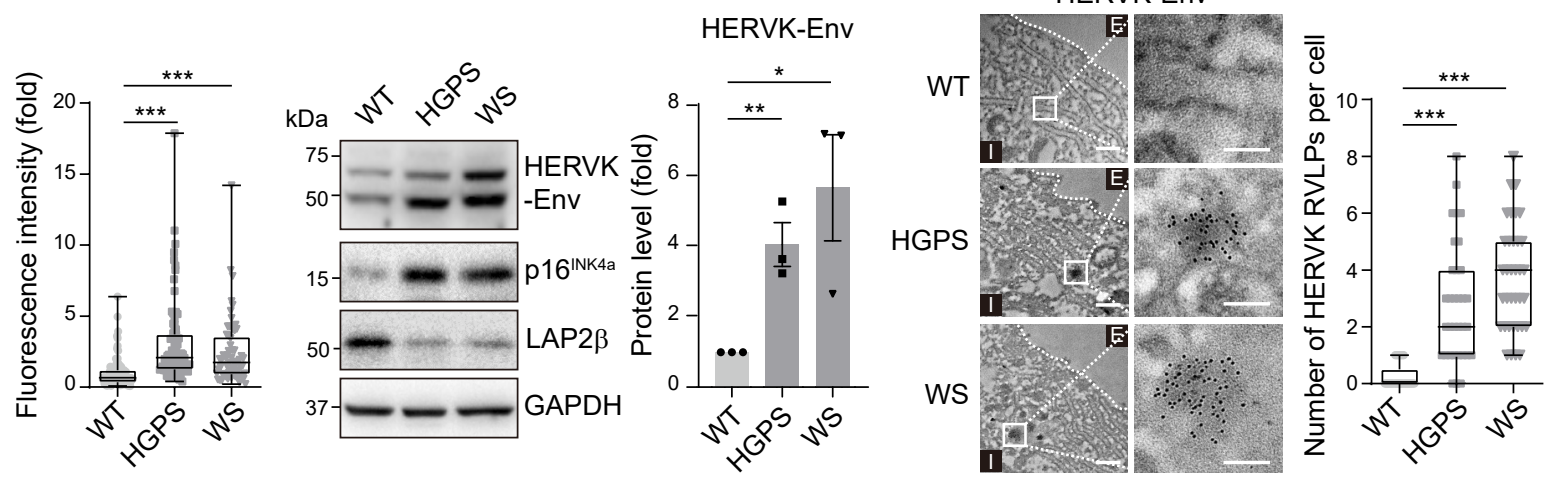
Fig. 2

A
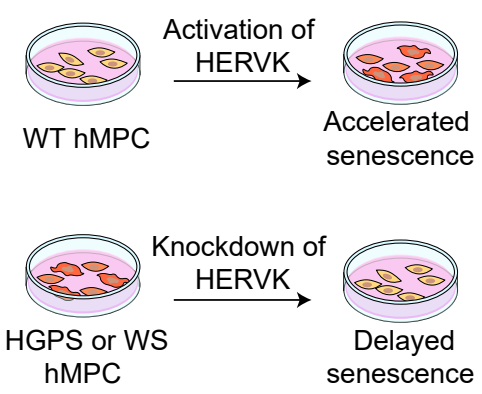

D

hMPC

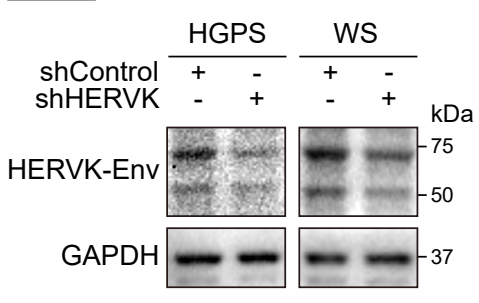

$\mathbf{F}$

RS hMPC
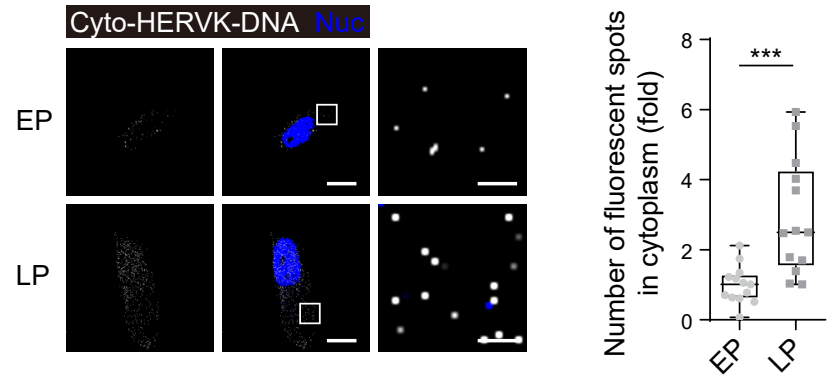

J

hMPC

$\underline{\text { hMPC }}$

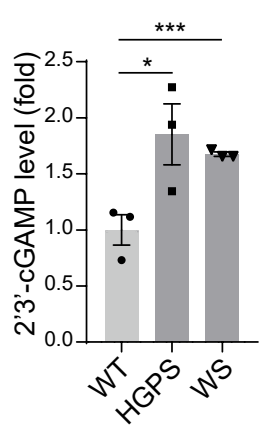

L

$\underline{\mathrm{hMPC}}$
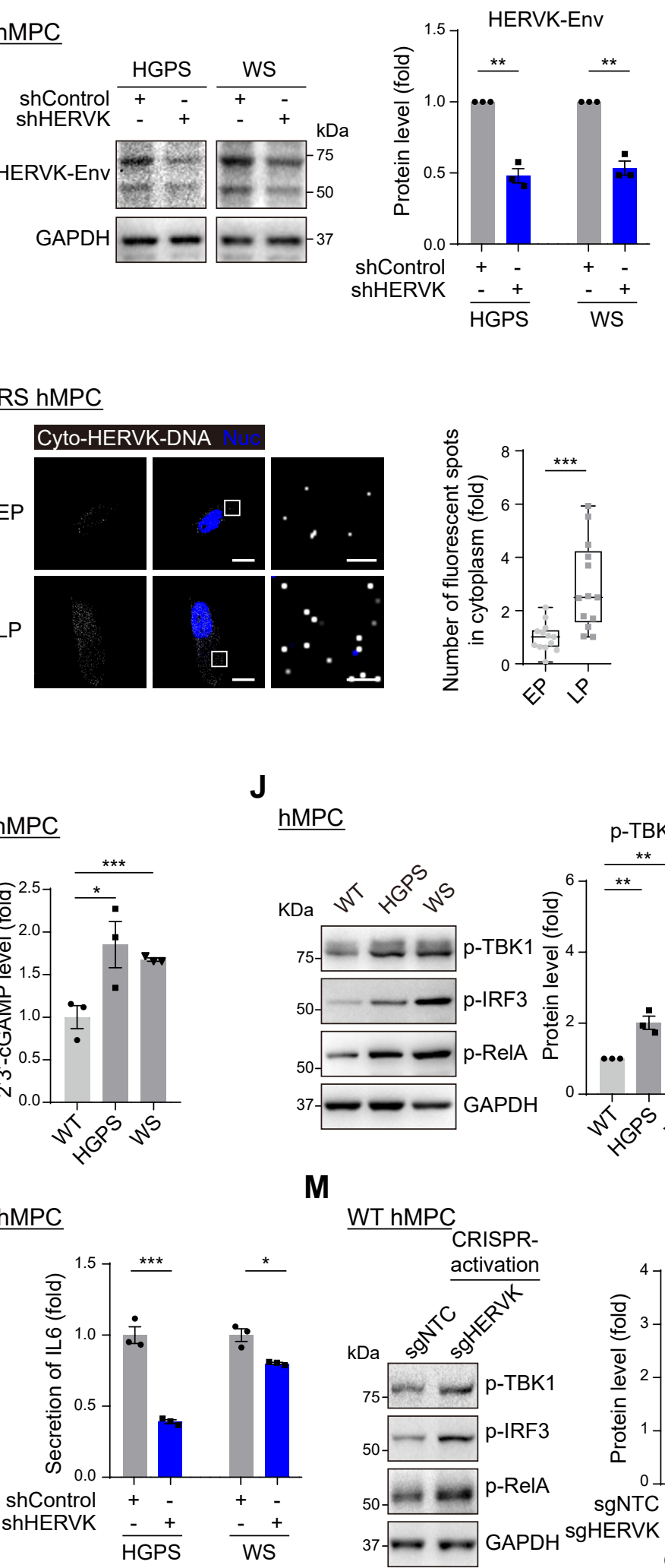

WT hMPC

CRISPR-

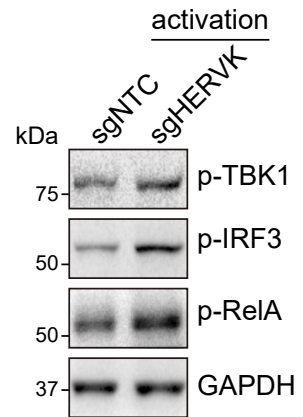

GAPDH ${ }^{\text {SgHERV }}$
B
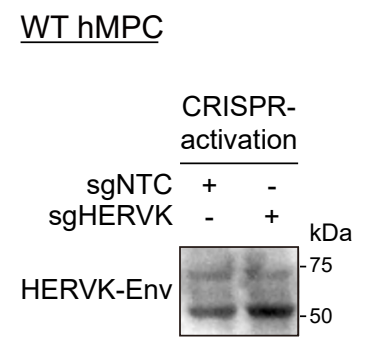

GAPDH

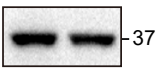

SgNTC
sgHERVK

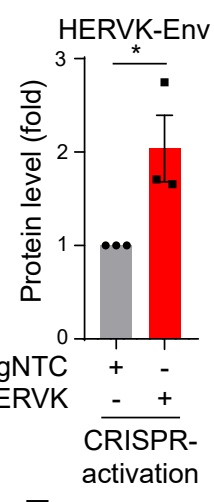

E

G

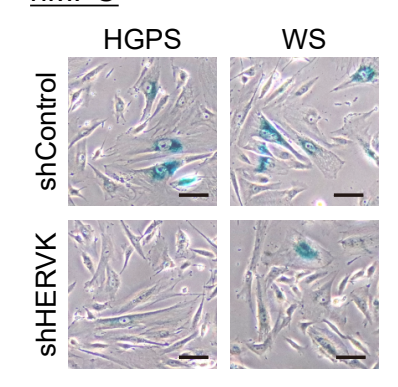

Viral nucleic acid

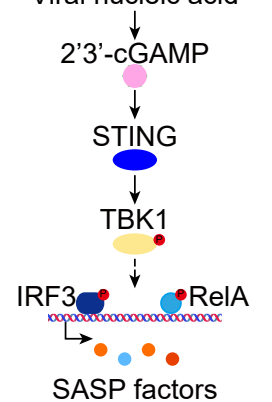

C

WT hMPC

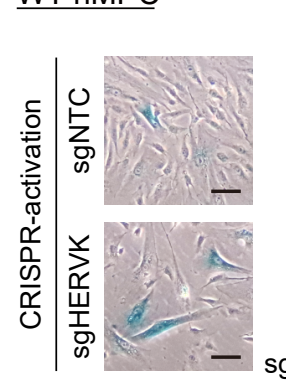

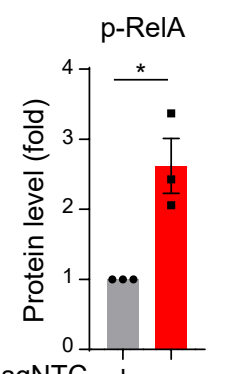

sgNTC

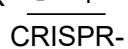

activation

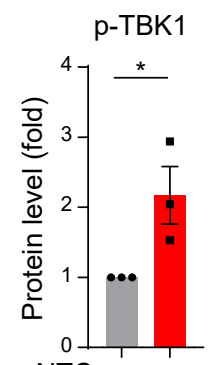

sgNTC

sgHERVK

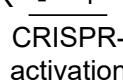

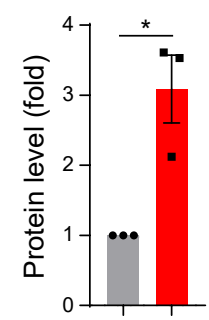

sgNTC sgHERVK

CRISPRactivation
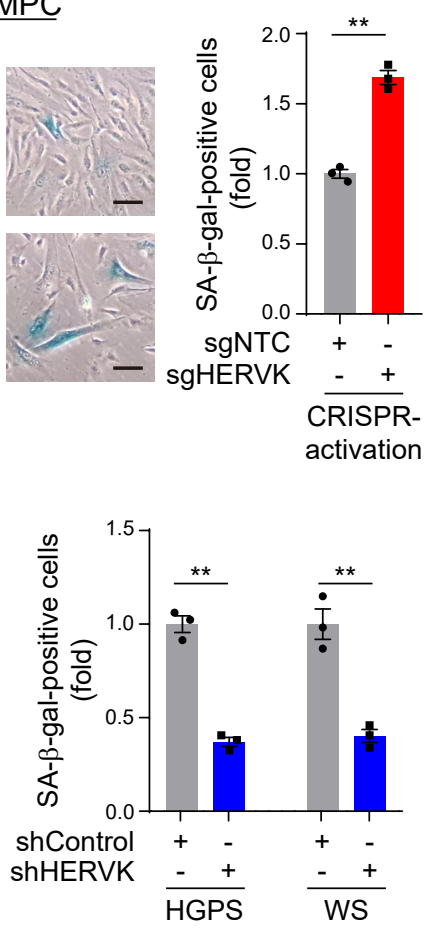

H

$\underline{\text { RS hMPC }}$

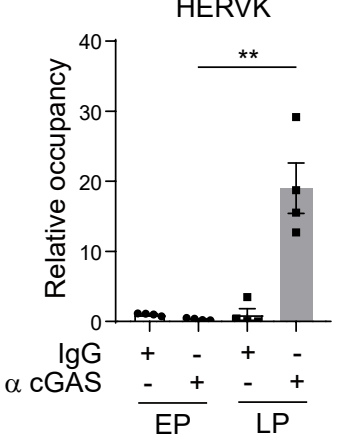

K

$\underline{\text { hMPC }}$

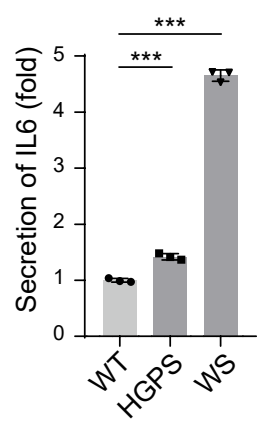

$\mathbf{N}$

WT hMPC
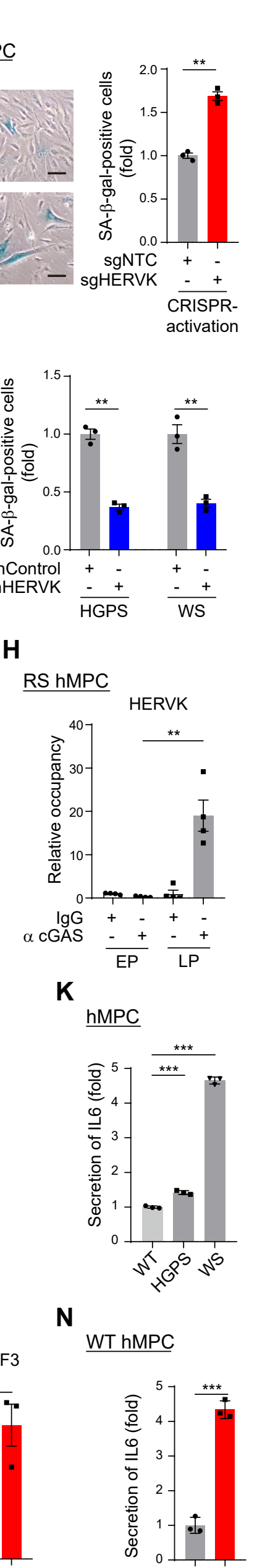

sgNTC sgHERVK CRISPRactivation 
bioRxiv preprint doi: https://doi.org/10.1101/2021.02.22.432260; this version posted February 22, 2021. The copyright holder for this

Fig. 3 preprint (which was not certified by peer review) is the author/funder, who has granted bioRxiv a license to display the preprint in

A

Senescent cells

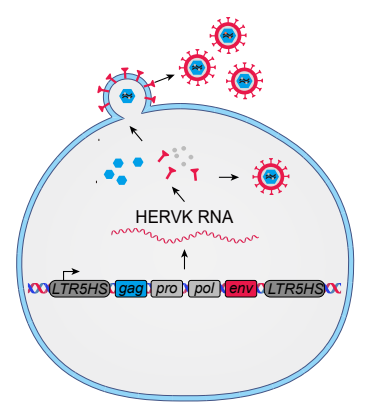

E

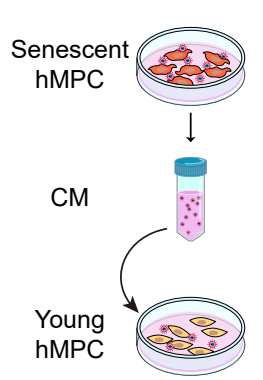

I

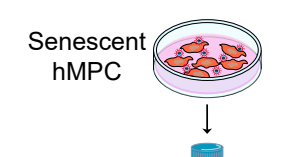

IP: $\alpha$ HERVK-Env $\downarrow{ }^{\circ}{ }^{\circ}$

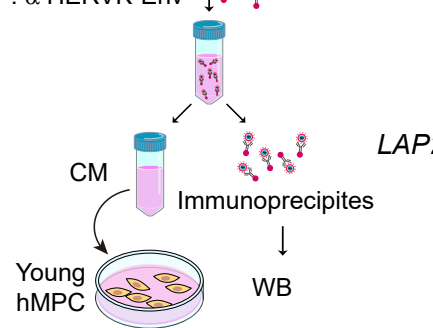

$\mathbf{F}$

J
B hMPC

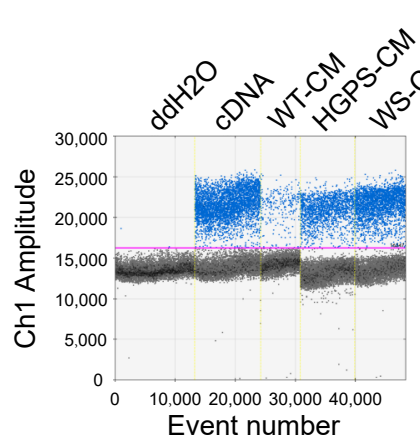

WT hMPC

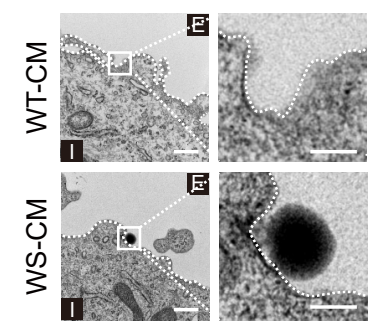

WT hMPC

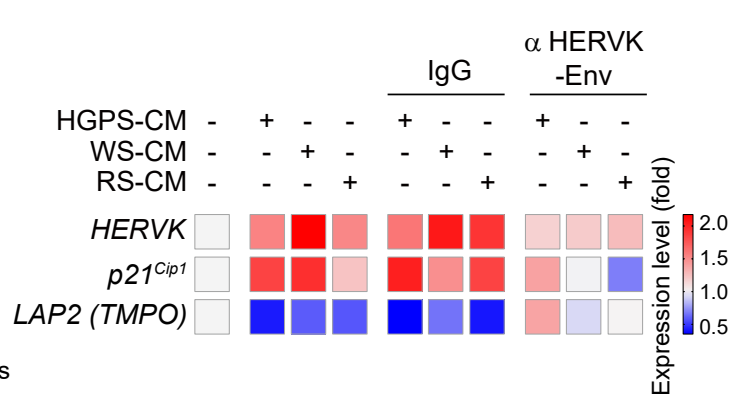

hMPC

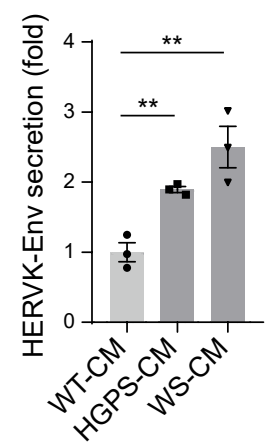

G

WT hMPC

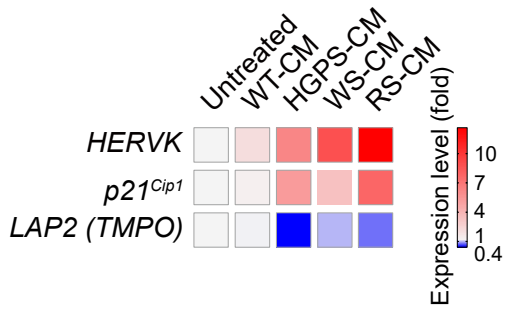

\section{K \\ WT hMPC}

$\underline{\mathrm{hMPC}}$

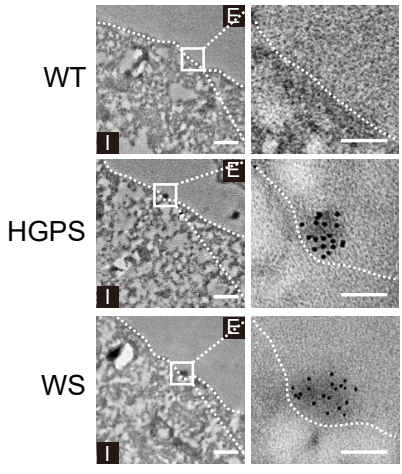

H

WT hMPC

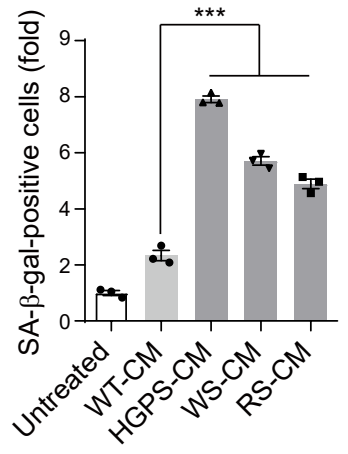

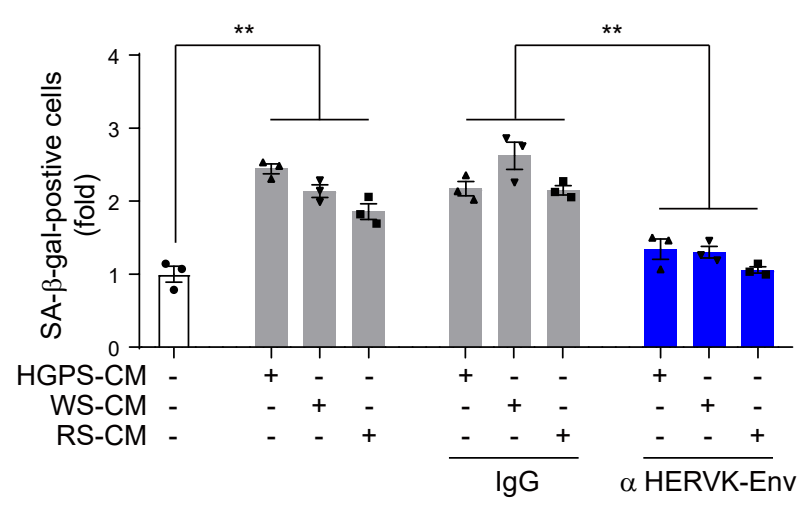


bioRxiv preprint doi: https://doi.org/10.1101/2021.02.22.432260; this version posted February 22, 2021. The copyright holder for this

Fig. 4

A

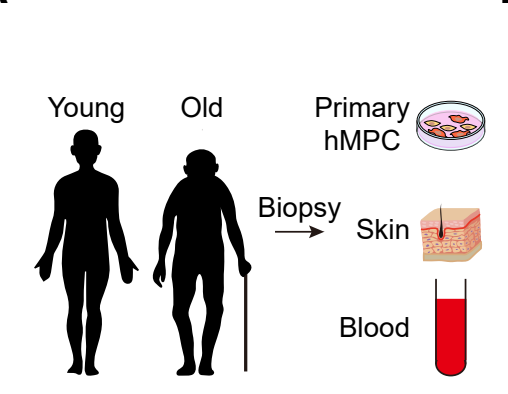

\section{Primary hMPC}

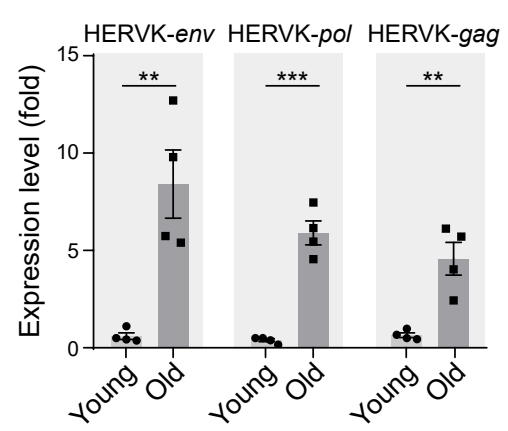

C

Skin

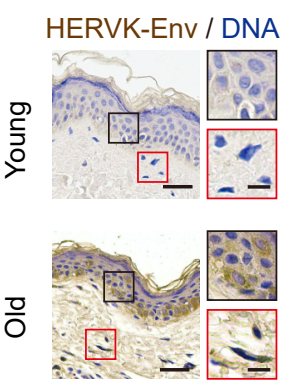

D

Blood

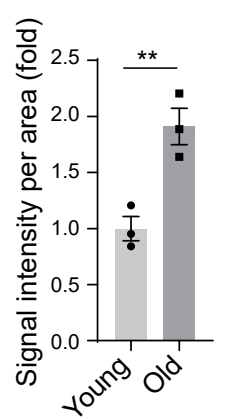

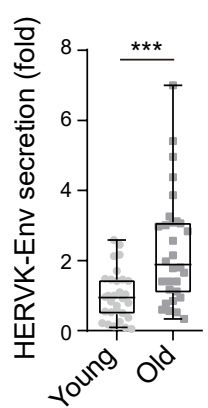


bioRxiv preprint doi: https://doi.org/10.1101/2021.02.22.432260; this version posted February 22, 2021. The copyright holder for this preprint (which was not certified by peer review) is the author/funder, who has granted bioRxiv a license to display the preprint in

Fig. 5 perpetuity. It is made available under aCC-BY-NC-ND 4.0 International license.

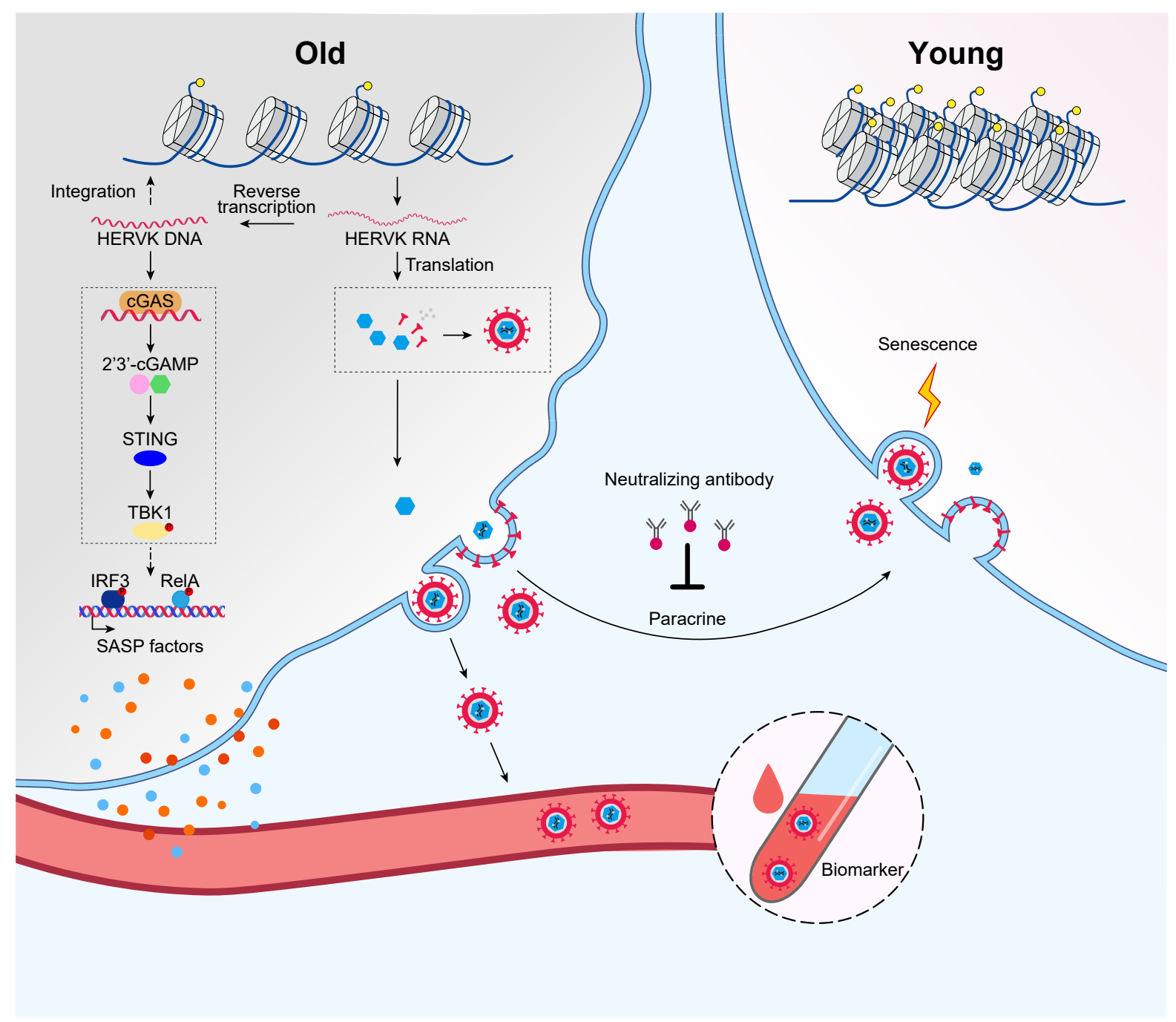

